\title{
PRODUTIVIDADE RELATIVA DOS SETORES PÚBLICO E PRIVADO EM EDUCAÇÃO: IMPACTOS SOBRE A ESCOLHA DA ESCOLA PELA FAMÍLIA
}

\author{
Rafael Terra* \\ Ana Carolina Zoghbi ${ }^{+}$ \\ Fabiana de Felício ${ }^{\ddagger}$
}

\begin{abstract}
Resumo
O objetivo deste trabalho é verificar se as famílias consideram o diferencial de produtividade educacional entre os setores privado e público (em termos de proficiências) ao decidirem sobre a escola de seus filhos. As funções de produção educacionais estimadas pelo modelo de Heckman revelam um diferencial de produtividade em favor do setor privado. Um aumento nos diferenciais de proficiências em matemática e leitura aumenta a probabilidade de as famílias escolherem o setor privado. Além disso, quanto maior a diferença de nível socioeconômico e do percentual de brancos entre os setores privado e público locais factíveis, maior é a probabilidade de a família optar pelo primeiro.
\end{abstract}

Palavras-chave: Escolha do Setor Educacional; Diferencial de Produtividade Inter-setorial em Educação; Modelo de Heckman; Probit.

\begin{abstract}
The purpose of this paper is to verify whether families take into account the educational productivity differentials between the private and public sectors (in terms of proficiency) when deciding on their children's schools. The production functions for each sector using Heckman Model revealed a productivity differential in favor of the private sector. An increase on the performance differential in Mathematics and Reading increases the odds of families choosing the private sector. Also, the higher the proportion of white students and the greater the difference in socioeconomic status of students in the private sector compared to public sector, the more likely a family will choose the private sector.
\end{abstract}

Keywords: Educational Sector Choice; Intersectoral Productivity Differential in Education; Heckman Model; Probit.

JEL classification: I21, C25, C52, D10

\footnotetext{
* Professor Adjunto do Departamento de Economia da UnB. E-mail: rflterra@yahoo.com.br

† Pós-Doutoranda FAPESP/EESP-FGV. E-mail: acpzoghbi@yahoo.com

‡ Diretora de pesquisas na Metas Avaliação e Proposição de Políticas Sociais. E-mail: fabiana.felicio@gmail.com
} 


\section{Introdução}

Políticas voltadas à ampliação das opções de escolha da escola para as famílias permitem que estas optem pela escola com características e valores prezados por elas, e.g. escolas religiosas ou não, pequenas ou grandes, bilíngue, com currículo mais tradicional ou alternativo, entre outras características (Levin 1991). Adicionalmente, tais políticas permitem que as famílias optem pelas escolas que ofereçam a qualidade de educação - em termos de capacidade de produzir maior desempenho ou "produtividade" - mais próxima daquela considerada ótima por elas, proporcionando aumento de eficiência alocativa e produtiva. Perdas de eficiência são inerentes à provisão de bens in-kind pelo setor público. No caso específico da provisão de educação isso é bem evidente. Considerando que os indivíduos possuam idiossincrasias que determinam diferentes preferências em relação às várias dimensões da educação - como qualidade, valores morais, entre outros - um nível fixo e homogêneo de educação pública, não é capaz de atender as preferências dos indivíduos, a não ser por coincidência.

O caso da qualidade da educação é o mais emblemático e, portanto, o foco deste estudo. Tendo em vista sua importância, considerando que o governo proveja uma qualidade fixa (exógena) igual q, os indivíduos atingiriam maiores níveis de utilidade se recebessem em dinheiro o custo de provisão de uma unidade desse bem. ${ }^{1}$ As famílias poderiam optar pela manutenção de seus filhos na escola pública ou matriculá-los em escolas privadas mais de acordo com suas preferências. O resultado, no caso, seria uma melhoria paretiana da economia. Note, no entanto, que o tamanho da melhoria depende da relação entre a qualidade da educação e os instrumentos de ampliação das opções de escolha, i.e., uma vez adotadas, tais políticas aumentariam a eficiência alocativa (ao ampliar as opções disponíveis) e, com o estímulo à competição introduzido pelas políticas, poderiam aumentar a eficiência produtiva geral (Anand et al. 2009). Exemplos de políticas desta natureza que podem conduzir a uma melhoria paretiana são os vouchers, o crédito educacional, deduções no imposto de renda devido, entre outros.

Duas questões são primordiais para avaliar se políticas para ampliação das alternativas educacionais são capazes de produzir melhorias paretianas, e o objetivo deste estudo consiste justamente em tentar responder tais questões. Primeiramente, é necessário saber se há diferenciais de qualidade (ou de pro-

\footnotetext{
${ }^{1}$ Nas Figuras 1, 2 e 3 do Apêndice Apêndice A, Gruber (2009) apresenta diferentes esquemas de provisão pública de educação são apresentados. Na Figura A.1, o governo oferece educação in-kind, o que altera a restrição orçamentária das famílias de AB para ACDB. Já na Figura A.2, o governo realiza transferências monetárias que só podem ser utilizadas em educação, com valor igual ao gasto educacional referente à provisão do bem in-kind. A restrição da família é deslocada para a direita no montante exato da transferência sem ampliar as possibilidades de consumo de outros bens, produzindo a restrição ACE. Na Figura A.3, observa-se o que ocorreria se o governo transferisse recursos em montante igual ao custo de provisão do bem in-kind e as famílias pudessem escolher se usariam esse recurso em educação ou em consumo de outros bens, resultando na restrição GE. Como se pode observar, as duas últimas políticas ampliam consideravelmente as opções das famílias, e geram utilidade maior ou igual àquela obtida quando o governo provê o bem in-kind. No entanto, note que a política baseada nas transferências monetárias sem restrições pode não ser uma opção ótima do ponto de vista social uma vez que educação é um bem meritório, e o governo precisa intervir para garantir que todos tenham acesso a um nível mínimo de qualidade da educação, mesmo que o montante demandado não seja ótimo do ponto de vista individual, e.g. no caso em que seja ótimo para as famílias despenderem todo o orçamento em consumo de outros bens exceto educação.
} 
dutividade) entre escolas da rede pública e privada. Note que neste estudo, "qualidade" e "produtividade" são termos empregados com o mesmo sentido, e refletem a tecnologia de produção educacional usadas pelas escolas. Frequentemente, a qualidade da escola se confunde com a qualidade do insumo escolar. Idealmente, o diferencial de produtividade entre todas as escolas deveria ser avaliado, mas os dados não permitem esse grau de detalhamento, uma vez que existiriam tantos diferenciais de produtividade quanto o número de combinações de escolas existentes (duas a duas) nas proximidades da residência da família. Entretanto, a análise de diferencial de produtividade entre redes de ensino é factível. Portanto, este estudo avalia o diferencial de produtividade entre as redes de ensino pública e privada. A hipótese subjacente é a de que as escolas públicas de cada localidade têm funções de produção idênticas entre si. O mesmo é assumido para escolas privadas. Isso pode ser razoável do ponto de vista do setor público, em que uma só rede chega a administrar escolas do estado inteiro. No caso da rede privada, há de se admitir que a hipótese seja bastante forte, pois a tecnologia de produção de educação pode variar em cada escola devido às diferentes gestões às quais as escolas estão sujeitas. Por outro lado, se a busca por maximização de lucros do setor privado resulta em eficiência produtiva, então todas as escolas do setor privado deveriam apresentar a mesma produtividade, i.e. deveriam produzir eficientemente.

Em seguida, este estudo questiona se as famílias levam em consideração esses diferenciais de produtividade para decidir onde matricular seus filhos. Caso não haja tais diferenciais, ou as famílias não se importem com estes quando decidem onde seus filhos irão estudar, então, não faria sentido a introdução de políticas de ampliação das possibilidades de escolha educacional das famílias.

Especificamente no Brasil, devido à grande desigualdade de renda, observase uma expressiva parcela de famílias praticamente sem opções de escolha acerca da escola em que matricularão seus filhos. Dessa forma, o objetivo desse trabalho é exatamente responder estas duas questões, com especial atenção aos efeitos dos diferenciais de produtividade sobre a escolha do setor educacional, questão não abordada até então em estudos para o Brasil. As hipóteses principais são as de que existe diferencial de produtividade entre os dois setores no Brasil (o setor privado é mais eficiente) - tal como encontrado por Oliveira et al. (2009) e França \& Gonçalves $(2009)^{2}$ —, e de que as famílias são capazes de identificar esse diferencial e levam-no em consideração em suas decisões sobre o setor educacional em que seus filhos serão matriculados. ${ }^{3}$

Nesse sentido, Goldhaber (1996) pressupõe em seu trabalho que os pais têm expectativas racionais, e assim, são capazes de fazer distinções entre os desempenhos de seus filhos se estes estudassem nos setores público ou privado. Usando dados de uma pesquisa educacional para uma coorte de alunos da $8^{\text {a }}$ série dos Estados Unidos em 1988 (NELS 88), o autor encontra evidências de

\footnotetext{
${ }^{2}$ Os dois trabalhos se valem de metodologias distintas. Oliveira et al. (2009) usam regressões quantílicas para avaliar os diferencias de produtividade público-privado, enquanto França \& Gonçalves (2009) usam Propensity Score Matching.

${ }^{3}$ Vale destacar uma hipótese adicional de que a função, ou tecnologia, de produção de desempenho não se altera, com a intensidade de uso de insumos. Isto é, caso os alunos da escola pública migrassem para o setor privado, sem implicar em um efeito congestionamento (aumento do tamanho de classe, aumento na razão aluno e professro, etc.), a tecnologia de produção do setor privado não se alteraria.
} 
que quanto maior o diferencial esperado de proficiências de matemática entre os setores privado e público maiores as chances das famílias dos alunos escolherem o setor privado.

Goldhaber (1999) e Jimenez \& Sawada (2001) resaltam outros fatores como determinantes da escolha entre os setores educacionais pelas famílias. Enquanto o primeiro autor encontra evidências de que um aumento dos gastos públicos em educação afeta a escolha do setor, aumentando a proporção de matrículas públicas no total, o segundo trabalho encontra evidências de que a expansão na oferta de vagas nas escolas públicas afeta a decisão de matrícula das famílias. Em relação às características da família, usando dados da Pesquisa de Orçamento Familiar de 2002/2003, Curi \& Menezes Filho (2009) destacam a renda familiar, a educação da mãe e o custo da educação como fatores importantes para a escolha do setor educacional. Long \& Toma (1988), com base em dados dos censos populacionais americanos de 1970 e de 1980, destacam ainda, que a cor do chefe de família e a religião são fatores decisivos para a decisão. James (1993), inclusive, afirma que em países desenvolvidos é comum que a rede privada de ensino advenha da competição e do empreendedorismo religioso. A autora também encontra as mesmas evidências para heterogeneidade linguística. Dessa forma, nesses países, a escolha pelo setor privado pelas famílias é explicada, em grande parte, pela heterogeneidade cultural (religiosa ou linguística).

Características dos potenciais colegas em cada setor também podem ser decisivas para a escolha da escola. Estevan (2009) destaca que a influência do efeito dos pares (peer effect) associado ao nível sócio-econômico médio da escola é um importante determinante do aprendizado da criança. Os pais, ao identificarem a importância desse fator buscam matricular seus filhos em escolas em que as características dos pares sejam mais favoráveis ao aprendizado. Como, em geral, as escolas privadas apresentam maior nível socioeconômico do que as escolas públicas, as famílias com melhores condições socioeconômicas optam por esse tipo de escola. Seguindo a mesma linha de raciocínio, Goldhaber (1996) encontra resultados que evidenciam a existência de uma maior propensão dos pais em matricularem seus filhos em escolas privadas comparativamente às escolas públicas quanto maior o diferencial de alunos brancos e de nível sócio econômico entre alunos das redes privada e pública.

Considerando a importância atribuída pela literatura ao efeito dos pares nas escolas, e ainda, o fato de que, na literatura nacional, tais fatores não foram explorados como determinantes das escolhas das famílias, um objetivo secundário deste trabalho é justamente verificar a importância desses fatores. Para isso, são analisados os efeitos da diferença entre os percentuais de alunos brancos em escolas privadas e públicas (factíveis de serem escolhidas por cada família) sobre as preferências das famílias por cada tipo de escola. O mesmo é feito em relação ao diferencial de nível socioeconômico.

Para responder as questões colocadas neste estudo, o modelo de Heckman é empregado para estimar as funções de produção de educação para os setores privado e público. Essa metodologia é distinta das usadas por Oliveira et al. (2009) e França \& Gonçalves (2009), o que por si só, já é digno de nota. Com isso, foi possível obter os diferenciais de produtividade e verificar seus efeitos em um modelo de escolha do setor educacional pela família.

Esse trabalho está dividido em seis seções, incluindo esta introdução. Na seção 2 encontra-se o modelo teórico de escolha da escola. Na seção 3 encontrase o modelo econométrico. Na seção 4 há uma descrição dos dados utilizados 
para construir as variáveis do modelo. Na seção seguinte encontram-se os resultados econométricos. Por fim, na seção 6 encontram-se as considerações finais.

\section{Modelo de escolha do setor educacional}

O pressuposto primordial do modelo teórico apresentado neste trabalho é o de que as famílias têm expectativas racionais e conseguem prever qual seria o desempenho dos seus filhos tanto no setor escolhido quanto no preterido (privado ou público). O modelo de escolha educacional se baseia em Goldhaber (1996). O intuito deste modelo é entender como a família decide onde matricular seus filhos. Assim, considere a família de um estudante i qualquer, cuja função utilidade indireta em relação à escolha do setor seja:

$$
V_{i s}=\delta_{0}+\delta_{1} D_{i s}+\delta_{2} Y_{i s}+\delta_{3} Q_{i s}
$$

Em que $D_{i s}$ é o desempenho esperado para o estudante $i$ por sua família caso estude no setor $s=1,2$, tal que 1 denota o setor privado e 2 denota o setor público. Esse desempenho é função das características dos alunos (background familiar), de características de seus colegas (peer effects) e características das escolas. Já $Y_{i s}$ representa a renda familiar exceto o gasto com mensalidade (que é igual a zero se o aluno estuda no setor público). Por fim, $Q_{i s}$ é um vetor de características dos potenciais colegas do estudante em cada setor.

Subtraindo $V_{i 1}$ de $V_{i 2}$ resulta em

$$
I_{i}=V_{i 1}-V_{i 2}=\delta_{1}\left(D_{i 1}-D_{i 2}\right)+\delta_{2} m_{i 1}+\delta_{3}\left(Q_{i 1}-Q_{i 2}\right)+\delta_{4} W_{i s}
$$

Em que $I_{i}$ é uma variável latente, tal que se $I_{i}>0$ a família escolhe o setor privado, e se $I_{i}<0$, escolhe o setor público. O termo $D_{i 1}-D_{i 2}$ representa o diferencial de desempenho esperado pelos pais entre os setores privado e público, e quanto maior esse diferencial maior deve ser a probabilidade de que os pais escolham a escola privada. O valor que a família do estudante $i$ pagaria se este estudasse em uma escola privada é representado por $m_{i 1}$ (em que se espera que $\delta_{2}<0$ ), que resulta da diferença entre a renda líquida (descontando o gasto com mensalidade) no setor privado e a renda se o aluno estudasse no setor público (em que o gasto é nulo). O termo $Q_{i 1}-Q_{i 2}$ representa o diferencial de características dos potenciais colegas do estudante $i$ em cada setor, e $W_{i s}$ é um vetor linha composto por características da família que afetam seus gostos (em nível) por cada tipo de escola, as quais não variam de acordo com o setor escolhido.

Considerando que $S_{i}=1$ denota a escolha pelo setor privado, a probabilidade de escolher cada setor será dada por:

$$
\begin{aligned}
& \operatorname{Pr}\left(S_{i}=1\right)=\operatorname{Pr}\left(I_{i}>0\right)=\delta_{1}\left(D_{i 1}-D_{i 2}\right)+\delta_{2} m_{i 1}+\delta_{3}\left(Q_{i 1}-Q_{i 2}\right)+W_{i s} \Theta>0 \\
& \operatorname{Pr}\left(S_{i}=0\right)=\operatorname{Pr}\left(I_{i} \leq 0\right)=\delta_{1}\left(D_{i 1}-D_{i 2}\right)+\delta_{2} m_{i 1}+\delta_{3}\left(Q_{i 1}-Q_{i 2}\right)+W_{i s} \Theta \leq 0
\end{aligned}
$$

A estimativa dos parâmetros desse modelo permite responder a questão principal deste trabalho, qual seja, se o diferencial de produtividade entre os setores educacionais desempenha algum papel na decisão das famílias pelo setor educacional de seus filhos. 


\section{Estratégia empírica}

Como mencionado na introdução, o procedimento para testar a hipótese principal deste trabalho envolve duas etapas. Primeiramente, são estimadas as funções de produção de educação (de proficiências) para cada um dos dois setores a fim de obter o diferencial de desempenho esperado para cada aluno entre os setores privado e público. A variável referente a este diferencial é usada, então, no modelo de escolha entre as redes de ensino. Como não é possível acompanhar os alunos ao longo do tempo, o exercício econométrico foi realizado com dados em cross section. Ao omitir variáveis fixas no tempo potencialmente correlacionadas com os regressores incluídos, e.g., habilidade, pode-se incorrer em estimativas enviesadas, o que constitui uma importante limitação do estudo.

A função de produção de proficiências para cada setor deve levar em consideração que os alunos se auto-selecionam para estudar em cada setor, de outra forma as estimativas dos parâmetros serão enviesadas. Assim, o modelo pode ser escrito como

$$
\begin{gathered}
D_{i s}=\alpha_{s}+Z_{i s} \Gamma_{s}+P_{i s} \Psi_{s}+E_{i s} \Phi_{s}+u_{i s} \\
S_{i s}=1\left[X_{i} \Omega_{s}+v_{i s}\right]>0
\end{gathered}
$$

Em que o subscrito $i$ representa o aluno e $s=1,2$ denota o setor em que o aluno estuda, igual a 1 quando privado e igual a 2 quando público. Em (4), $D_{i s}$ representa o desempenho em matemática ou leitura do aluno $i$, no setor $s$. Os vetores-coluna de parâmetros são representados por $\Gamma_{s}, \Psi_{s}$ e $\Phi_{s}$. $O$ vetor-linha de covariadas $Z_{i s}$ contém variáveis referentes às características dos alunos, $P_{i s}$ contém variáveis de peer effect, e $E_{i s}$ é composto por variáveis referentes às características da escola e dos professores. ${ }^{4}$ Em (5), se $s=1, S_{i 1}$ assume valor igual a 1 se o aluno escolheu o setor privado e 0 se escolheu o setor público, e se $s=2$, então $S_{i 2}$ é igual a 1 para o setor público e 0 para o setor privado. O vetor-linha $X_{i}$ de covariadas contém variáveis observadas para todos os alunos (ambos os setores), além de uma variável explicativa excluída de (4) para permitir identificação do modelo. Essa variável excluída é denominada "razaoescolaspop" e se refere à oferta de escolas privadas no município. ${ }^{5}$ Finalmente, os termos uis e vis representam os termos de erro das equações (4) e (5).

As hipóteses essenciais para identificação do modelo são: (a) $X_{i}$ e $S_{i s}$ são sempre observáveis e $D_{i s}$ é observável somente quando $S_{i s}=1$; (b) $u_{i s}, v_{i s}$ são independentes de $X_{i}$ com média zero; (c) $v_{i s} \sim \mathcal{N}(0,1)$ e (d) $E\left(u_{i s} \mid v_{i s}\right)=\gamma_{s} v_{i s}$. Assim, pode-se aplicar o modelo de seleção de Heckman (1979), que permite estimar os parâmetros corrigindo o potencial viés, e produz a seguinte forma geral estimável:

$$
E\left(D_{i s} \mid X_{i}, S_{i s}=1\right)=\alpha_{s}+Z_{i s} \Gamma_{s}+P_{i s} \Psi_{s}+E_{i s} \Phi_{s}+\gamma_{s} \lambda\left(X_{i} \Omega_{s}\right)
$$

\footnotetext{
${ }^{4}$ As variáveis explicativas inseridas nas equações de desempenho são semelhantes às usadas em Rivkin et al. (2005), Goldhaber (1996), McEwan (2001) e McEwan \& Carnoy (2000). Especificações similares podem ser encontradas também em e Oliveira et al. (2009) e França \& Gonçalves (2009).

${ }^{5}$ Ver a descrição desta variável na Tabela A.1.
} 
Em que $\lambda\left(X_{i} \Omega_{s}\right)$ é a razão de Mills inversa. Se $\gamma_{s}=0$, e dada a hipótese (c), então os parâmetros poderiam ser estimados consistentemente por OLS. Já se $\gamma_{s} \neq 0$, então, ao não considerar o último termo (razão de Mills) na regressão da amostra selecionada, ter-se-ia um problema equivalente ao de variáveis omitidas. Para estimar (6) é necessário obter a razão de Mills em um primeiro estágio representado em (5),onde a variável dependente denota a escolha dos setores privado ou público, e ao qual convencionou-se denominar "Probit reduzido". Note, no entanto, que o diferencial de desempenho esperado entre setores representado pelo termo $\left(D_{i 1}-D_{i 2}\right)$ em (3), e o diferencial de características dos potenciais colegas representado por $\left(Q_{i 1}-Q_{i 2}\right)$ não são incluídos nesse Probit reduzido. Assumindo que a variável razaoescolaspop seja exogenamente determinada, i.e., não seja correlacionada com as variáveis omitidas supracitadas e nem com quaisquer outras possíveis variáveis omitidas, é possível obter estimativas não enviesadas da razão de Mills. ${ }^{6}$

Com a razão de Mills como regressor, pode-se estimar o segundo estágio do modelo de Heckman por OLS, obtendo-se a função de produção educacional da amostra selecionada. Todavia, para que as estimativas das funções de produção educacionais dos setores público e privado não sejam enviesadas, é necessário considerar uma hipótese adicional de que eventuais variáveis omitidas não estejam correlacionadas com os regressores incluídos em (6). ${ }^{7}$ Mas, caso estejam correlacionadas, a direção e a magnitude dos vieses devem ser as mesmas para ambos os setores. Outra hipótese subjacente é a de que as funções de produção de cada setor são estáveis em relação à intensidade no uso dos insumos.

Em seguida, é obtida a nota esperada de cada aluno para cada setor educacional usando os parâmetros estimados do modelo dado pelas equações (4) e (5). Depois se tira a diferença entre os desempenhos esperados nos setores privado e público para cada aluno, a qual pode ser representada por:

$$
\text { difprofic }_{i}=\widehat{D_{i 1}}-\widehat{D_{i 2}}
$$

Essa é a principal variável de interesse no modelo de escolha do setor educacional, a qual pode ser interpretada como um diferencial de produtividade entre os setores privado e público. McEwan \& Carnoy (2000) estimam medidas de diferenciais de produtividade entre setores semelhantes a essa, e também considerando que os diferenciais se dão somente no intercepto ou somente nas inclinações. Uma possibilidade aventada pelos autores é a de que diferenciais de produtividade na verdade não existam, e as diferenças

\footnotetext{
${ }^{6}$ Tal hipótese é semelhante à suposição clássica de unidades consumidoras atomizadas, sem poder de influência sobre a quantidade ofertada ou preço do bem. A mesma variável é usada para identificar a equação de seleção de um modelo multinomial por McEwan (2001), para depois medir diferenças de produtividade entre mais de dois setores. O autor realiza um teste empírico que sugere que a variável essa variável não tem relação direta com desempenho acadêmico depois de inseridos todos os controles socioeconômicos e de insumos escolares e, portanto, constitui uma variável adequada para identificar a equação de seleção no modelo de Heckman.

${ }^{7}$ Uma possível forma de endogeneidade é levantada por Tiebout (1956), segundo o qual os indivíduos se sorteiam entre as localidades que provêm cestas de bens públicos mais próximas de suas preferências. Nesse caso, as características das famílias e das escolas podem não ser exógenas. Esse problema é de difícil identificação e correção. No entanto, se considerada a existência de custos de migração suficientemente altos, esse problema não se verificaria. Neste trabalho desconsiderou-se o a possibilidade de viés de Tiebout. Outra forma de endogenidade é destacada por McEwan \& Carnoy (2000) e se refere às habilidades dos alunos e outras características não observáveis correlacionadas com os regressores.
} 
observadas se devam somente à autosseleção. Todavia, McEwan (2001) não encontra evidências conclusivas para excluir a possibilidade de diferenças de produtividade, e inclusive encontra evidências de diferenças intersetoriais entre escolas públicas e privadas não participantes de programas de vouchers chilenos após corrigir a autosseleção. Note também que esta estratégia de estimação do diferencial entre setores é distinta daquelas utilizadas por Oliveira et al. (2009) — que usam regressões quantílicas — e por França \& Gonçalves (2009) - que usam Propensity Score Matching.

Duas variáveis importantes referentes ao diferencial de características dos potenciais colegas em cada setor (representado pelo termo $Q_{i 1}-Q_{i 2}$ em (3)) são as diferenças entre a proporção de brancos e o nível socioeconômico dos alunos das redes privada e pública que constituem alternativas factíveis de serem escolhidas para um aluno $i$, denominadas $D b r a n c o_{i}$ e $D N S E_{i}$, respectivamente. Ou seja, se este aluno $i$ frequenta a escola privada, o cálculo destes indicadores é baseado na diferença entre o indicador de sua escola (privada) e o indicador da rede pública em seu município ou em sua microrregião (quando não houver informações para o município). Já se este aluno frequenta a escola pública, o cálculo é baseado na diferença entre os indicadores da rede privada do município ou da microrregião (quando não houver informações para o município) e os da escola deste aluno, que é pública. ${ }^{8,9}$

Estas duas variáveis são consideradas bastante importantes pela literatura, a qual argumenta que, controlando pelo efeito da própria renda, os pais procuram escolas cujo perfil dos potenciais colegas de seus filhos esteja associado a indivíduos normalmente mais bem-sucedidos, isto é, brancos e com alto nível socioeconômico. Note, no entanto, que há uma hipótese implícita razoável de que a decisão individual por uma ou outra escola de determinado setor não afeta as características dos potenciais colegas e, portanto, não se observa endogeneidade nesse caso.

Assim, considerando $S_{i}=1$ para o setor privado, ${ }^{10}$ a contraparte empírica de (3) fica da seguinte forma:

$$
\operatorname{Pr}\left[S_{i}=1\right]=\pi_{0}+\pi_{1} \text { difprofic }_{i}+\pi_{2} m_{i 1}+\pi_{3} \text { Dbranco }_{i}+\pi_{4} D N S E_{i}+W_{i} \Pi+\varepsilon_{i}
$$

Em que $m_{i 1}$ é o gasto com mensalidade se o aluno $i$ estudasse no setor privado. ${ }^{11} \mathrm{O}$ vetor linha $W_{i}$ contém covariadas que, por hipótese, captam as preferências da família em relação à matrícula nos setores público ou privado, como renda, cor, etc. ${ }^{12} \mathrm{O}$ termo $\Pi$ é um vetor coluna de parâmetros, e $\varepsilon_{i}$ é o

\footnotetext{
${ }^{8}$ Para os alunos da rede privada, $0,02 \%$ dos indicadores de DNSE foram calculados com informações da microrregião. Isto é, praticamente todos os alunos da rede privada tinham escolas públicas como alternativa em seus municípios. Por outro lado, para $12,26 \%$ dos alunos da rede pública, não havia alternativa privada de ensino em seus municípios, e informações da microrregião foram usadas para o cálculo do indicador DNSE. Em relação aos indicadores Dbranco, para alunos da rede privada, todos os indicadores foram calculados com informações dos próprios municípios, enquanto para alunos da rede pública, 9,70\% das informações advieram da microrregião.

${ }^{9}$ Note que aproximadamente $45,0 \%$ dos municípios da amostra do SAEB apresentam escolas privadas, enquanto que para o Brasil esse percentual é de 31,4\%. Essa diferença se refere ao fato de a amostra do SAEB ser representativa de alunos e não de municípios.

${ }^{10}$ Note que neste caso não há o subscrito s diferenciando cada setor.

${ }^{11} \mathrm{Na}$ Tabela A.1 pode ser observado que esta se trata de uma variável estimada, pois não há informações sobre mensalidade no SAEB.

${ }^{12}$ Variáveis de controle semelhantes são encontradas em Goldhaber (1996).
} 
termo de erro não correlacionado com os regressores. O método de estimação usado neste caso é o Probit (doravante denominado Probit Estrutural), com erros padrão de variáveis estimadas corrigidos por Bootstrap.

Outros fatores podem afetar a decisão das famílias. As famílias podem preferir a rede privada pelo fato de os professores desta não entrarem em greve, com efeitos na quantidade de ausências no trabalho dos pais ou na probabilidade de participação no mercado de trabalho. Ou ainda, algumas famílias podem preferir matricular seus filhos na escola privada, pois acreditam que estas desenvolvem melhor as habilidades não cognitivas dos estudantes e também permitem ampliar o "capital social", i.e., podem aumentar o número de relacionamentos interpessoais com potencial de produzir maior retorno econômico. Supõe-se neste trabalho que o vetor $W$ de características em (8) e os diferenciais de nível socioeconômico representado pelo indicador multidimensional DNSE sejam suficientes para captar as preferências e motivações das famílias, direta ou indiretamente.

Finalmente, como se pode notar, a estratégia de identificação usada neste trabalho requer uma série de hipóteses de ortogonalidade entre o regressores e termos de erro. A estrutura dos dados em cross-section torna essas hipóteses relativamente fortes. Se dados em painel estivessem disponíveis para este estudo, as hipóteses de ortogonalidade não seriam tão fortes, uma vez que seria possível remover os efeitos não observáveis fixos no tempo e correlacionados com as variáveis explicativas incluídos nas regressões. Dummies de unidades federativas são incluídas nas especificações econométricas para captar parte do efeito fixo, mas dificilmente isso seria suficiente para eliminar todo o efeito não observável. Portanto, deve-se ter em mente que as conclusões obtidas são limitadas pela estrutura e disponibilidade dos dados.

\section{Dados}

As principais variáveis construídas para este estudo se baseiam nos bancos de alunos (matemática e leitura), professores, escolas e turmas do Sistema Nacional de Avaliação da Educação Básica (SAEB) de 2003. São utilizados também os Censos da Educação Básica (Censo Escolar) de 2003 e de 2005 e o Censo dos Profissionais do Magistério (Censo Magistério), só disponível em 2003, razão pela qual este ano foi escolhido para análise. Os dados se referem aos alunos da $8^{\text {a }}$ série, e quando não existiam informações para esse grupo, foram usadas as informações do segundo ciclo ( $5^{\mathrm{a}}$ a $8^{\mathrm{a}}$ série) do Ensino Fundamental (EF) ou do EF como um todo. Para três variáveis, em especial, são utilizadas bases de dados diferentes: a renda per capita, a mensalidade e a razão entre o número de escolas privadas e o total de alunos com idade adequada (de 11 a 15 anos) para cursar de $5^{\mathrm{a}}$ a $8^{\mathrm{a}}$ séries.

Para obter a primeira variável, dados de background familiar dos alunos da $8^{a}$ série da Pesquisa Nacional por Amostra de Domicílios (PNAD) foram usados em uma regressão (por OLS) da renda familiar per capita sobre variáveis também presentes no SAEB e correlacionadas com a renda. Com a estimativa dos coeficientes, obteve-se a renda predita para os alunos do SAEB baseada em dados de contexto sócio-econômico das famílias dos alunos.

O mesmo procedimento foi realizado para estimar o gasto com mensalidade usando dados da Pesquisa de Orçamentos Familiares de 2002/2003. Mas, 
como a amostra para alunos de $8^{\text {a }}$ série que pagam mensalidade é muito pequena, foram usadas informações familiares de alunos de $5^{\mathrm{a}}$ a $8^{\mathrm{a}}$ séries.

Por fim, a variável referente à razão entre o número de escolas privadas e a população na faixa etária de 11 a 15 anos do município, que consiste na variável de identificação do modelo de seleção de Heckman (excluída do segundo estágio), foi obtida dividindo o número de escolas privadas obtido junto ao Censo Escolar de 2003 pela Projeção da População de 2003 obtida junto ao DATASUS. Na Tabela A.1 encontram-se as variáveis usadas nos modelos econométricos, as descrições de cada uma, a fonte das informações, e em que etapa do procedimento foram usadas, ou seja, no modelo de seleção de Heckman ou no Probit Estrutural. Nas Tabelas A.2 e A.3 encontram-se as estatísticas descritivas (média e desvio-padrão) das variáveis usadas nestes dois modelos para as amostras de matemática e leitura, respectivamente. Como se pode notar nessas tabelas, as médias de proficiências em matemática e leitura dos alunos da rede privada são cerca de 1 desvio-padrão (cerca de cinquenta pontos) maiores do que as verificadas entre os alunos de escolas públicas. Por outro lado, as características dos alunos são bastante diferentes entre os que estudam nas redes privada e pública, o que sugere a existência do problema de autoseleção na amostra.

\section{Resultados}

Os resultados das estimações das funções de produção de educação pública e privada pelo modelo de Heckman para as amostras de matemática e leitura encontram-se nas Tabelas A.4 ( $1^{\circ}$ estágio) e A.5 ( $2^{\circ}$ estágio). Curiosamente, a razão de Mills não foi significativa para a equação do setor privado, mas foi altamente significativa para a equação do setor público, sugerindo que o problema de autoseleção está presente. Como se pode notar, os coeficientes, em geral, apresentam os sinais esperados, mas são bastante diferentes entre os dois setores. Um simples teste de diferença nos coeficientes (teste de Chow) rejeita a igualdade entre os coeficientes a $1 \%$ de significância. Isso sugere que os retornos em cada setor são, de fato, distintos. Ressalta-se que todas as regressões incluem dummies de Unidades da Federação com o intuito de considerar na estimação do diferencial de produtividade o fato de que as alternativas de estudo (rede pública ou privada) de cada aluno são limitadas geograficamente. A inclusão de dummies de município ou microrregiões seria ideal. No entanto, é importante notar que no SAEB, a maioria dos municípios têm apenas poucos alunos avaliados. A inclusão de dummies de município e até mesmo de microrregiões no modelo estimado por Máxima Verossimilhança potencialmente sofreria do problema de variáveis incidentais, que produziriam estimativas viesadas dos parâmetros. Além disso, o modelo estimado por Máxima Verossimilhança com essas variáveis incluídas apresenta problemas de convergência.

Para calcular a diferença de produtividade entre os setores, primeiramente, obteve-se a nota esperada (predita) para os alunos da escola privada (com base na própria função de produção educacional), e também as notas esperadas dos alunos da escola pública se estivessem na escola privada usando os coeficientes obtidos na equação do setor privado. Esses valores foram reunidos em uma única variável que informava a nota esperada no setor privado para todos os alunos. Em seguida, obteve-se a nota esperada dos alunos das escolas pública e privada com base nos coeficientes da equação do setor público. Esses valo- 
res constituíram uma variável que informava a nota esperada no setor público para todos os alunos.

Na Figura 1, encontram-se as distribuições das proficiências esperadas em matemática em cada setor para os alunos das redes privada e pública. Em geral, nota-se que a rede privada é mais produtiva (pode-se dizer neste contexto que é mais eficiente), sustentando uma das hipóteses principais do trabalho. No painel da esquerda, referente aos alunos da rede privada, nota-se que as notas esperadas de matemática na rede escolhida são bastante superiores àquelas que obteriam se os mesmos alunos estudassem em escolas públicas. Para os alunos da rede pública, por outro lado, essa diferença existe, mas é menor. Adicionalmente, por esses gráficos e nas Tabelas A5 e A6, é possível verificar que o diferencial de produtividade é maior para os alunos na parte superior da distribuição, confirmando os resultados encontrados por Oliveira et al. (2009). Mas, ao contrário dos resultados dos autores, o diferencial de produtividade entre os setores privado e público é positivo em quase todos os percentis da distribuição. Essa vantagem de produtividade também é observada por McEwan \& Carnoy (2000) em escolas privadas chilenas não participantes do programa de vouchers e escolas católicas participantes do programa.
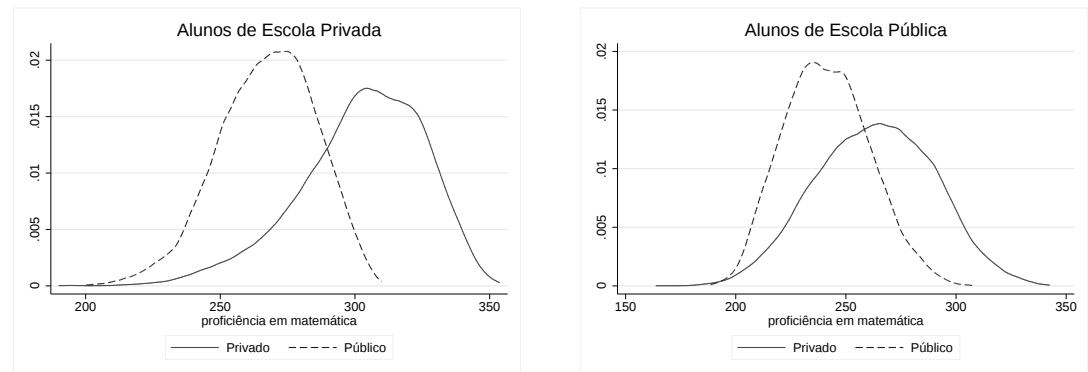

Figura 1: Produtividade esperada em cada setor para alunos de escolas privadas e públicas - amostra de matemática
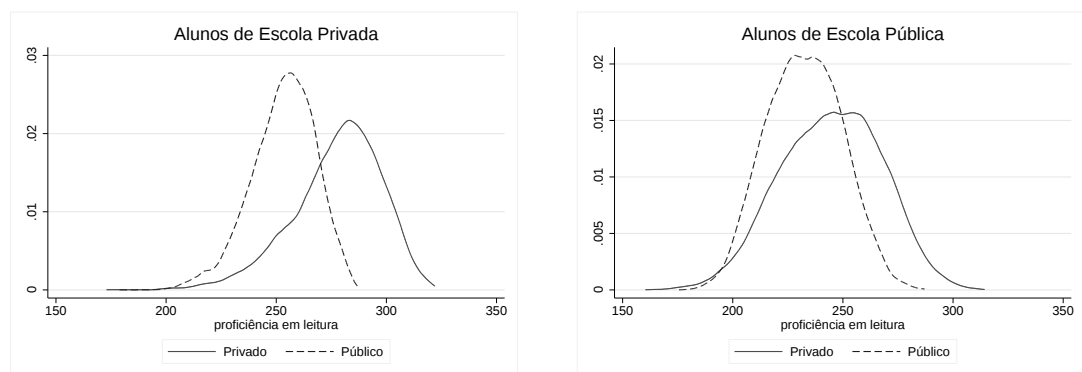

Figura 2: Produtividade esperada em cada setor para alunos de escolas privadas e públicas - amostra de leitura

Para a amostra de leitura (Figura 2) os resultados são semelhantes, tanto para os alunos das escolas privadas quanto para os das públicas. Mas a magnitude das diferenças de produtividade entre os setores são menores. Tal resultado era previsível uma vez que a literatura argumenta que a influência da escola no conhecimento acumulado em matemática deve ser maior do que a 
influência sobre a capacidade de leitura (mais presente no cotidiano dos alunos).

Com o desempenho esperado para cada aluno em cada setor, obteve-se o diferencial de produtividade representado em (7). Nas Tabelas A5 e A6 podem-se verificar as médias gerais dessa variável para as amostras de matemática e de leitura, iguais a 26,5 e 16,3, respectivamente. Entre os alunos da rede privada, o diferencial de produtividade em matemática é de 36,5 pontos, e entre os alunos da rede pública é de 22,9 pontos. Já o diferencial para a amostra de leitura é de 25,5 entre os alunos da rede privada, e de 13,0 entre os alunos da rede pública.

Tendo a estimativa do diferencial de produtividade entre setores, o passo seguinte consistiu em estimar o modelo de decisão da família acerca da matrícula de seus filhos, o modelo Probit Estrutural mencionado anteriormente. Os efeitos marginais estimados do modelo se encontram na Tabela 1 (ver Tabela A.1 para uma descrição de cada variável usada no modelo). Note que os erros-padrão dos coeficientes das variáveis "rendapcpt", "mensalidade" e "difprofic" foram corrigidos por Bootstrap já que se tratam de variáveis estimadas. Além disso, tanto para a amostra de matemática quanto para a de leitura, há especificações com e sem as variáveis "DNSE" e "Dbranco". A inclusão dessas variáveis reduz bastante a amostra, pois várias escolas do Censo do Magistério de 2003 não reportaram informações. Além disso, é interessante ver como a inclusão dessas variáveis afeta os demais coeficientes do modelo.

Como se pode verificar na Tabela 1, no modelo I, para a amostra de matemática, a probabilidade de frequentar a escola privada entre os alunos do sexo feminino é menor (1,43 pontos percentuais - p.p. - menor). Os alunos brancos, como esperado, apresentam maiores chances de frequentar escolas deste setor (1,36 p.p maiores). Alunos com algum dos pais ausentes do domicílio, por outro lado, têm menos chances $(0,73$ p.p e 0,48 p.p a menos para as ausências da mãe e do pai, respectivamente). Pais com escolaridade superior a 8 anos têm maiores chances de matricularem seus filhos na escola privada do que os pais com escolaridade inferior, mas esse efeito é maior para aqueles com escolaridade entre 11 e 14 anos (17,11 p.p e 7,89 p.p maiores para mães e pais com esse nível de escolaridade, respectivamente) do que para os pais com escolaridade igual a 15 anos ou mais (11,36 p.p. e 5,86 p.p maiores para mães e pais com esse nível de escolaridade, respectivamente). Isso é o contrário do que se esperava, ou seja, um efeito marginal sempre crescente de acordo com a escolaridade da família.

A renda per capita familiar tem efeito positivo sobre a probabilidade dos pais matricularem seus filhos no setor privado (um aumento de $\mathrm{R} \$ 1,00$ na renda familiar per capita tem um efeito positivo de 0,04 p.p. sobre a probabilidade de a família escolher uma escola privada). A mensalidade, por sua vez, apresentou efeito marginal positivo (o aumento de $\mathrm{R} \$ 1,00$ na mensalidade aumenta em 0,12 p.p. a probabilidade de escolha de uma escola privada), ao contrário do que se imaginava. Goldhaber (1996) também encontra este resultado. A razão disso, além do fato de ser uma variável estimada e, portanto, constituir uma proxy, reside no fato de a mensalidade refletir a qualidade da escola. Assim, a escola privada não consiste em um único bem, mas em vários tipos de bens com qualidades diferentes, o que faz com que a mensalidade não capte um efeito preço puro.

A infraestrutura doméstica, por sua vez, construída para captar o interesse dos pais em educação e cultura, de acordo com os resultados do modelo I da 
Tabela 1, afeta positivamente a probabilidade de as famílias escolherem escola privada (o aumento de 1 ponto no indicador de infra estrutura, que varia de 0 a 4, aumenta a probabilidade de frequentar escola privada em 1,8 p.p.). Os resultados dos efeitos marginais das variáveis de controle para as demais equações, inclusive para amostra de leitura, apresentam os mesmos sinais e magnitudes semelhantes às encontradas no modelo I. A exceção fica por conta da variável "tamanho da familia", que apresenta sinais diferentes entre as equações I e III referentes às amostras de matemática (em que o aumento de um membro na família implica em uma redução da probabilidade em 1,04 p.p.) e de leitura (em que o aumento de um membro na família implica em um aumento de 2,42 p.p.), o que pode estar ligado a algum efeito ambíguo. ${ }^{13}$

Ao incluir no modelo as variáveis de interesse "Dbranco" e "DNSE" (equações II e IV da Tabela 1) os resultados sustentam as hipóteses de que as famílias consideram os efeitos de pares em suas decisões sobre o setor educacional em que estudam seus filhos. O diferencial no percentual de alunos brancos entre as alternativas privada e pública factíveis de serem escolhidas por cada aluno afeta positivamente a probabilidade de escolher o setor privado (para a amostra de matemática - no modelo II —, o aumento de 1 p.p. no diferencial de cor aumenta em 0,09 p.p. a probabilidade de optar pelo setor privado). Esse resultado sugere uma tendência de segregação étnica entre os setores. O diferencial de nível socioeconômico (DNSE) entre as redes pública e privada factíveis também afeta positivamente a probabilidade de escolha do setor privado (para a amostra de matemática — no modelo II — um aumento de 1 ponto no indicador aumenta em 12,29 p.p. a probabilidade de escolha de escolas privadas), reforçando a ideia de que os pais decidem acerca das escolas de seus filhos com base nas características relativas dos potenciais colegas, enxergando nessas características uma medida de qualidade da escola e de sucesso futuro de seus filhos.

A principal variável de interesse, o diferencial de produtividade esperado entre setores (variável "difprofic"), apresentou sinal positivo e significativo, sustentando a hipótese principal deste trabalho. O efeito marginal estimado para o modelo I - referente à amostra de matemática - indica que um aumento de um ponto no diferencial de desempenho (medido pela escala SAEB) em favor do setor privado aumenta a probabilidade de escolher tal setor em 1,17 p.p.. Na especificação II, onde são inseridas as variáveis "Dbranco" e "DNSE", o efeito marginal cai para 0,87 p.p., mas continua significativo a $1 \%$. Para a amostra de leitura os efeitos são ainda maiores. Na especificação III, um aumento de um ponto no diferencial de desempenho entre setores aumenta em 2,10 p.p. a probabilidade de escolha do setor privado, quase o dobro do que se verifica na especificação semelhante para a amostra de matemática (especificação I). Inserindo os demais regressores em IV esse efeito marginal se reduz para 1,43 p.p., mas continua significativo a $1 \%$ e representa quase $o$ dobro do efeito marginal observado para a amostra de matemática na especificação II. ${ }^{14}$

\footnotetext{
${ }^{13}$ Por exemplo, um arranjo familiar em que a mãe é solteira e mora com um filho é mais comum entre famílias pobres, com menores chances de escolherem a escola privada. Já um arranjo familiar com pai e mãe e um único filho é mais comum entre famílias com maior poder aquisitivo e com maior propensão de matricularem seus filhos em escolas privadas. A partir daí, quanto maior o número de filhos maiores as chances de a família ser pobre, com menos condições de dar uma atenção adequada à educação de seus filhos.

${ }^{14}$ Mesmo usando dados em cross section, os resultados foram similares aos encontrados por
} 
Tabela 1: Estimativas do modelo de escolha do setor educacional (Público $=0$ ou Privado $=1)$ - Efeitos Marginais do modelo Probit Estrutural com as variáveis fixas em suas médias amostrais

\begin{tabular}{|c|c|c|c|c|}
\hline \multirow{2}{*}{$\operatorname{Pr}($ escola privada $)$} & \multicolumn{2}{|c|}{ Matemática } & \multicolumn{2}{|c|}{ Leitura } \\
\hline & $\mathrm{I}$ & II & III & IV \\
\hline Efeitos Marginais & 0,2499 & 0,1222 & 0,2324 & 0,1092 \\
\hline sexo & $\begin{array}{c}-0,0143^{* *} \\
(0,0073)\end{array}$ & $\begin{array}{r}-0,0058 \\
(0,0063)\end{array}$ & $\begin{array}{c}-0,0521^{* * *} \\
(0,0075)\end{array}$ & $\begin{array}{c}-0,0348^{* * *} \\
(0,0063)\end{array}$ \\
\hline branco & $\begin{array}{c}0,0136 \\
(0,0076)\end{array}$ & $\begin{array}{c}0,0170^{* * *} \\
(0,0065)\end{array}$ & $\begin{array}{c}0,0256^{* * *} \\
(0,0075)\end{array}$ & $\begin{array}{c}0,0220^{* * *} \\
(0,0062)\end{array}$ \\
\hline maeausente & $\begin{array}{r}-0,0073 \\
(0,0133)\end{array}$ & $\begin{array}{c}-0,0046 \\
(0,0117)\end{array}$ & $\begin{array}{c}-0,0525^{* * *} \\
(0,0116)\end{array}$ & $\begin{array}{c}-0,0313^{* * *} \\
(0,0092)\end{array}$ \\
\hline paiausente & $\begin{array}{r}-0,0048 \\
(0,0086)\end{array}$ & $\begin{array}{r}-0,0101 \\
(0,0073)\end{array}$ & $\begin{array}{r}-0,0037 \\
(0,0084)\end{array}$ & $\begin{array}{r}-0,0033 \\
(0,0069)\end{array}$ \\
\hline escmae 8 a 10 & $\begin{array}{c}0,1077^{* * *} \\
(0,0133)\end{array}$ & $\begin{array}{c}0,0774^{* * *} \\
(0,0141)\end{array}$ & $\begin{array}{c}0,2972^{* * *} \\
(0,0153)\end{array}$ & $\begin{array}{c}0,2475^{* * *} \\
(0,0183)\end{array}$ \\
\hline escmae11a14 & $\begin{array}{c}0,1711^{* * *} \\
(0,0115)\end{array}$ & $\begin{array}{c}0,1137^{* * *} \\
(0,0116)\end{array}$ & $\begin{array}{c}0,2923^{* * *} \\
(0,0122)\end{array}$ & $\begin{array}{c}0,2320^{* * *} \\
(0,0136)\end{array}$ \\
\hline escmae15oumais & $\begin{array}{l}0,1136^{* * *} \\
(0,0153)\end{array}$ & $\begin{array}{l}0,0760^{* * *} \\
(0,0146)\end{array}$ & $\begin{array}{c}0,1681^{* * *} \\
(0,0158)\end{array}$ & $\begin{array}{l}0,1276^{* * *} \\
(0,0161)\end{array}$ \\
\hline escpai8a10 & $\begin{array}{c}0,0250^{*} \\
(0,0129)\end{array}$ & $\begin{array}{c}0,0186 \\
(0,0121)\end{array}$ & $\begin{array}{c}0,0477^{* * *} \\
(0,0132)\end{array}$ & $\begin{array}{c}0,0280^{* *} \\
(0,0118)\end{array}$ \\
\hline escpai11a14 & $\begin{array}{c}0,0789^{* * *} \\
(0,0118)\end{array}$ & $\begin{array}{c}0,0611^{* * *} \\
(0,0116)\end{array}$ & $\begin{array}{c}0,0601^{* * *} \\
(0,0116)\end{array}$ & $\begin{array}{l}0,0261^{* * *} \\
(0,0101)\end{array}$ \\
\hline escpai15oumais & $\begin{array}{c}0,0586^{* * *} \\
(0,0149)\end{array}$ & $\begin{array}{c}0,0380^{* * *} \\
(0,0135)\end{array}$ & $\begin{array}{c}-0,0215 \\
(0,0136)\end{array}$ & $\begin{array}{c}-0,0143 \\
(0,0108)\end{array}$ \\
\hline rendapcpt & $\begin{array}{l}0,0004^{* * *} \\
(0,0000)\end{array}$ & $\begin{array}{l}0,0003^{* * *} \\
(0,0000)\end{array}$ & $\begin{array}{c}0,0004^{* * *} \\
(0,0000)\end{array}$ & $\begin{array}{c}0,0003^{* * *} \\
(0,0000)\end{array}$ \\
\hline mensalidade & $\begin{array}{c}0,0012^{* * *} \\
(0,0001)\end{array}$ & $\begin{array}{c}0,0007^{* * *} \\
(0,0001)\end{array}$ & $\begin{array}{l}0,0009^{* * *} \\
(0,0001)\end{array}$ & $\begin{array}{l}0,0006^{* * *} \\
(0,0001)\end{array}$ \\
\hline tamanhofamilia & $\begin{array}{c}-0,0104^{* * *} \\
(0,0026)\end{array}$ & $\begin{array}{c}-0,0039 \\
(0,0024)\end{array}$ & $\begin{array}{c}0,0242^{* * *} \\
(0,0027)\end{array}$ & $\begin{array}{l}0,0176^{* * *} \\
(0,0023)\end{array}$ \\
\hline infradomestica & $\begin{array}{c}0,0180^{* * *} \\
(0,0038)\end{array}$ & $\begin{array}{c}0,0086^{* * *} \\
(0,0033)\end{array}$ & $\begin{array}{l}0,0049 \\
(0,0038)\end{array}$ & $\begin{array}{l}0,0003 \\
(0,0032)\end{array}$ \\
\hline difprofic & $\begin{array}{l}0,0117^{* * *} \\
(0,0004)\end{array}$ & $\begin{array}{l}0,0087^{* * *} \\
(0,0004)\end{array}$ & $\begin{array}{c}0,0210^{* * *} \\
(0,0006)\end{array}$ & $\begin{array}{c}0,0143^{* * *} \\
(0,0005)\end{array}$ \\
\hline DNSE & - & $\begin{array}{l}0,1229^{* * *} \\
(0,0039)\end{array}$ & - & $0,1177^{* * *}$ \\
\hline Dbranco & 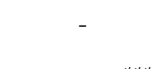 & $\begin{array}{c}0,0009^{* * *} \\
(0,0002)\end{array}$ & 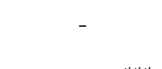 & $\begin{array}{l}0,0003 \\
(0,0002)\end{array}$ \\
\hline razaoescolaspop & $\begin{array}{c}196,4851^{* * *} \\
-134,390\end{array}$ & $\begin{array}{l}135,2951^{* * *} \\
-125,560\end{array}$ & $\begin{array}{c}192,2241^{* * *} \\
-135,130\end{array}$ & $\begin{array}{l}98,5393^{* * *} \\
-115,120\end{array}$ \\
\hline Dummies de UF & $\operatorname{sim}$ & $\operatorname{sim}$ & $\operatorname{sim}$ & $\operatorname{sim}$ \\
\hline N. Obs & 24713 & 19720 & 24887 & 17918 \\
\hline$(-2) x \log$ verossimilhança & 4096305 & 2216925 & 3894545 & 2093325 \\
\hline LR chi quadrado & 8021,42 & 4570,77 & 8224,99 & 4425,65 \\
\hline Pseudo $R^{2}$ & 0,49 & 0,57 & 0,52 & 0,60 \\
\hline
\end{tabular}


Com esses resultados, foi realizado um exercício adicional para identificar como a família do aluno representativo responde a variações no diferencial de desempenho (produtividade). Esse exercício é interessante, pois mostra que o aluno representativo brasileiro vive em condições socioeconômicas precárias, o que restringe suas opções de escolha sobre o setor educacional. Além disso, esse exercício permite vislumbrar como a produtividade pode afetar a migração de alunos entre as redes, o que pode ter implicações tanto em termos de peer effects na escola pública, quanto em termos de gasto público em educação por aluno.

Na Figura 3 e na Tabela 2, pode-se verificar esse exercício. É importante notar que o diferencial médio de produtividade em matemática deste aluno representativo é de 26,8 pontos (ver cruzamento das linhas tracejadas na Figura 3 ou a Tabela 2), cerca de meio desvio-padrão, o que é bastante expressivo. No painel esquerdo da figura, percebe-se que, dado o diferencial médio, a probabilidade de o indivíduo médio escolher o setor privado é de 12,5\%. Portanto, dadas as suas características, a família desse indivíduo prefere matriculá-lo na escola pública, o que reflete a realidade brasileira. Para fazer com que sua família fique indiferente entre matriculá-lo na escola privada ou na pública (probabilidade igual a 50\% representada pela linha vermelha), o diferencial necessário de produtividade entre os setores deveria ser de 53,8 pontos ( $\mathrm{Ta}$ bela 2), o dobro do diferencial médio observado. Para leitura a análise é semelhante, o diferencial de produtividade necessário para que a família do indivíduo médio fique indiferente entre os setores seria de 32,6 pontos, o que representa o dobro do diferencial médio observado para este indivíduo (igual a 16,3 pontos de acordo com a Tabela 2).
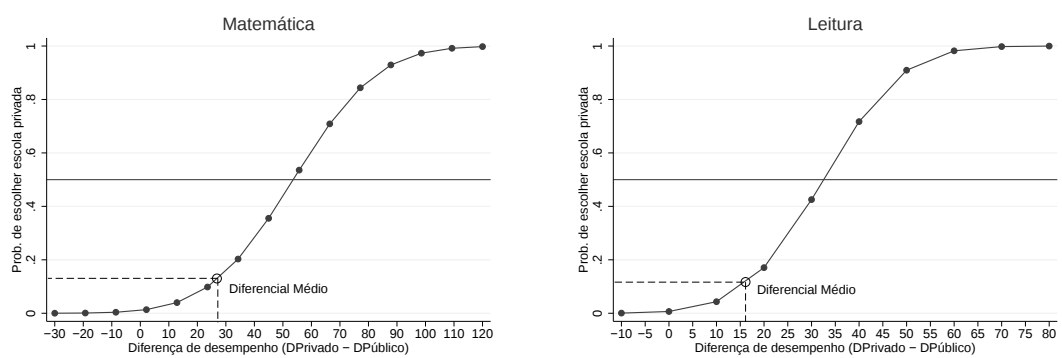

Fonte: Elaboração Própria.

Figura 3: Impacto do diferencial de produtividade entre os setores (com tudo mais avaliado na média) sobre a probabilidade de escolha do setor educacional (público ou privado) pela família do indivíduo médio.

O mesmo exercício foi feito para alunos representativos de diferentes quartos de renda com o intuito de analisar como classes sociais distintas respondem aos diferenciais de produtividade entre os setores educacionais. Todas as características foram fixadas na média de cada quarto de renda. Os efeitos de variações na diferença de produtividade para cada quarto de renda

Goldhaber (1996) que também testa um modelo de escolha educacional com variáveis de controle semelhantes, mas com os dados em estrutural de painel. Para a variável "DNSE", o autor encontrou coeficientes iguais a 0,265 e 0,165 para as amostra de matemática e leitura, respectivamente. Já para "dfprofic", os coeficientes foram iguais a 0.071 e 0.037 para as amostras de matemática e leitura, respectivamente. 
encontram-se na Figura 4 e na Tabela 2. A distribuição de renda parece ser um pouco assimétrica, daí os gráficos não serem simétricos entre os quartos de renda. O ponto encontrado pelo cruzamento das linhas tracejadas informa a probabilidade de escolha do setor privado associada ao diferencial média de produtividade de cada quarto de renda. Como se pode observar na Figura 4 para a amostra de matemática, no $1^{\circ}$ quarto (mais pobre), dado o diferencial de 20,8 pontos, a probabilidade de o indivíduo representativo escolher o setor privado é praticamente nula (igual a $0,6 \%$ de acordo com a Tabela 2). Mesmo para o indivíduo representativo do $3^{\circ}$ quarto de renda (o $2^{\circ}$ mais rico), a probabilidade de escolher uma escola é de somente $13,7 \%$. No quarto de renda mais rico, por outro lado, a probabilidade de escolha do setor privado associada a uma diferença média de 35,2 pontos é igual a $81,5 \%$. Isso evidencia a desigualdade social marcante entre os alunos brasileiros. Apesar de os alunos de quartos mais pobres (predominantemente de escolas públicas) também poderem auferir grandes benefícios se trocassem o setor público pelo privado, somente os alunos do quarto mais rico (predominantemente de escolas privadas) tem condições de realizar escolhas sobre o setor.
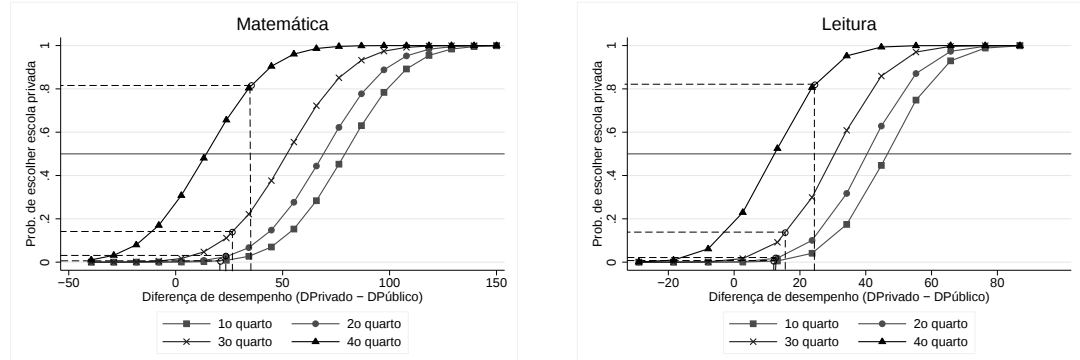

Fonte: Elaboração Própria.

Figura 4: Impacto do diferencial de produtividade entre os setores sobre a probabilidade de escolha do setor educacional (público ou privado) pelas famílias de cada quarto de renda (todas as características avaliadas na média de cada quarto).

Ainda de acordo com a Tabela 2 e com a Figura 4, para a amostra de matemática, pode-se notar que o diferencial de produtividade intersetorial requerido para que a família do indivíduo do quarto mais rico fique indiferente entre estudar em escolas públicas ou privadas é de 14,2 pontos em matemática, pouco abaixo do diferencial médio de 26,8 pontos. Já para a família do indivíduo do quarto mais pobre ( $1^{\circ}$ quarto) ficar indiferente entre os dois setores, o diferencial esperado de desempenho deveria ser de 79,3 pontos, o que sugere que esse fator não exerce grande influência na escolha das famílias do quarto de renda mais pobre. Para a amostra de leitura a situação é bastante semelhante, mas os pais parecem ser mais sensíveis aos diferenciais de produtividade em leitura do que em matemática; possivelmente por se tratar de uma disciplina cujo desempenho acadêmico é mais facilmente percebido no dia-a-dia. 
Tabela 2: Diferencial de produtividade que faz o indivíduo ficar indiferente entre os setores público e privado

\begin{tabular}{lcccc}
\hline & \multicolumn{4}{c}{ Ponto Médio } \\
\cline { 2 - 5 } & Matemática & Pr(esc. Privada) & Leitura & Pr(esc. Privada) \\
\hline Indivíduo Médio & 26,8 & $12,5 \%$ & 16,3 & $10,9 \%$ \\
\hline Ind. $1^{\circ}$ quarto & 20,8 & $0,6 \%$ & 12,4 & $0,5 \%$ \\
Ind. $2^{\circ}$ quarto & 23,5 & $2,5 \%$ & 13,0 & $1,8 \%$ \\
Ind. 3 $3^{\circ}$ quarto & 26,6 & $13,7 \%$ & 15,5 & $12,5 \%$ \\
Ind. $4^{\circ}$ quarto & 35,2 & $81,5 \%$ & 24,4 & $82,1 \%$ \\
\hline & & Ponto de Indiferença & \\
\hline & Matemática & Pr.Indiferença & Leitura & Pr.Indiferença \\
Indivíduo Médio & 53,8 & $50 \%$ & 32,6 & $50 \%$ \\
Ind. $1^{\circ}$ quarto & 79,3 & $50 \%$ & 46,6 & $50 \%$ \\
Ind. 2 $2^{\circ}$ quarto & 69,3 & $50 \%$ & 40,5 & $50 \%$ \\
Ind. 3 $3^{\circ}$ quarto & 52,1 & $50 \%$ & 30,5 & $50 \%$ \\
Ind. 4 $4^{\circ}$ quarto & 14,2 & $50 \%$ & 12,3 & $50 \%$ \\
\hline
\end{tabular}

Fonte: Elaboração Própria

\section{Uma breve discussão sobre possíveis políticas}

Os resultados sugerem que a produtividade relativa do setor educacional (que constitui também uma medida de qualidade) é um aspecto valorizado pelas famílias, mas a renda restringe fortemente a liberdade de escolha do setor. Em condições socioeconômicas mais favoráveis, e.g. iguais ao do indivíduo médio do $4^{\circ}$ quarto de renda, o diferencial médio de produtividade observado entre os setores determinaria a escolha de uma escola privada. No entanto, a maior parte dos estudantes brasileiros não tem escolha. Nesse sentido, a introdução de políticas voltadas à ampliação das possibilidades de escolha das famílias que ampliasse a renda disponível permitiria que estas escolhessem o setor educacional com base nas diferenças de produtividade, atenuando as restrições às escolhas impostas pelas características socioeconômicas. Isso resultaria em uma menor ineficiência alocativa. Por outro lado, o aumento das possibilidades de escolha levaria à maior competição entre as escolas, incentivando aumentos generalizados de produtividade (aumentaria a eficiência produtiva).

Existem algumas políticas públicas que poderiam ser consideradas no Brasil para aumentar as possibilidades de escolha do setor educacional pelas famílias via aumento da renda disponível. Uma delas é o voucher educacional. ${ }^{15} \mathrm{~A}$ ideia do voucher é a de que o governo pague um subsídio às famílias, as quais podem escolher a escola que irá receber o recurso, entre públicas e privadas. Esse recurso só pode ser gasto em educação, seguindo a visão de que educação é um bem meritório que deve ser provido visando um maior bem-estar social, mesmo que do ponto de vista da família não seja ótimo consumir educação.

A teoria econômica prevê aumento de eficiência produtiva e alocativa com a introdução de vouchers. Apesar de não ser o foco deste trabalho mostrar que o voucher é uma ferramenta de melhoria do desempenho por permitir aos estudantes acesso à escolas com maior eficiência produtiva, é importante conhe-

\footnotetext{
${ }^{15}$ Para uma discussão mais aprofundada sobre vouchers ver Levin (1991).
} 
cer vantagens e limitações dessa política. Anand et al. (2009), por exemplo, avaliam a experiência chilena usando dados de alunos da $4^{\mathrm{a}}$ série. Os autores encontram evidências de que a distribuição de vouchers a serem utilizados em escolas privadas para uma amostra de alunos de baixa renda tem um impacto positivo em seus desempenhos acadêmicos comparativamente a alunos de escolas públicas com probabilidades semelhantes de serem selecionados a receberem o benefício. Da mesma forma, Rouse (1998), usando de dados experimentais, encontra evidências de que crianças participantes do programa de voucher implementado em Wisconsin - primeiro Estado americano a implementar o programa de voucher —, apresentaram melhores desempenhos em matemática.

Por outro lado, McEwan \& Carnoy (2000), não encontram evidências significativas de maior produtividade (denominada "efetividade" pelos autores) entre escolas não religiosas participantes do programa de vouchers do Chile, que representam a maioria das escolas criadas após a reforma que introduzira os vouchers em 1980. Mas escolas religiosas participantes apresentaram maior produtividade. McEwan (2001), após controlar por autosseleção em um modelo de Heckman multinomial, encontra diferenciais de produtividade somente entre escolas privadas não participantes de programas de vouchers e escolas públicas, os diferenciais entre o setor público e outros tipos de escola participantes do programa somem após considerado o termo de autosseleção. Mayer et al. (2002) e Krueger \& Zhu (2004), com dados experimentais sobre a distribuição de voucher na cidade de Nova York, não encontram diferenças significativas nos testes padronizados entre alunos sorteados e não sorteados para participarem do programa. Esses resultados não conclusivos podem ser decorrentes da ambiguidade dos efeitos dos pares, pois vouchers têm o potencial de segregarem alunos de acordo com preferencias e status das famílias, tirando alunos com melhores desempenhos de escolas socialmente vulneráveis, e que se beneficiavam da presença destes, e os transferindo para escolas com pouco a ganhar com suas presenças. Por outro lado, os alunos transferidos podem se beneficiar da convivência com "pares" com melhores desempenhos acadêmicos. ${ }^{16}$ Uma maior homogeneidade das escolas permite também focar mais precisamente nas reais necessidades de cada aluno. No geral, deve-se ter em mente que os ganhos em termos de desempenho dos alunos, quando existentes, são pequenos. Mas, considerando que poucas (ou nenhuma) políticas públicas em educação têm grandes efeitos no desempenho, e levando em conta, ainda, que esta é uma política de baixo custo, é necessário considerá-la seriamente.

O desenvolvimento do mercado de crédito educacional aliado à provisão de vouchers constitui também uma alternativa para ampliar as opções de escolha. Entretanto, por falta de colateral para oferecer no ato do empréstimo, esse mercado é ausente no Brasil, e seu desenvolvimento pode ser de difícil solução. Na ausência desse mercado, outra possibilidade de ampliar as escolhas envolve a criação de um fundo para a Educação Básica que conceda crédito educacional para as famílias de baixa renda. Os estudantes que tivessem acesso a esse crédito começariam a pagar o empréstimo realizado pelos seus pais quando concluíssem os estudos e ingressassem no mercado de trabalho. Possivelmente, isso estimularia a conclusão do ensino superior, uma vez que

\footnotetext{
${ }^{16}$ McEwan \& Carnoy (2000) também alertam para a relação entre segregação de alunos e peer effects, mas não se propõem a estimar a direção ou a magnitude dessa relação.
} 
seria introduzido um componente intertemporal no problema de escolha do consumidor que incentivaria a escolha do nível educacional que maximizasse os ganhos futuros. Em um primeiro momento, esse crédito poderia ser financiado por recursos públicos, mas a partir do período seguinte seria custeado pelos pagamentos realizados pelas pessoas que utilizaram o crédito nos períodos anteriores, formando uma espécie de cooperativa de crédito semelhante às já existentes nos Estados Unidos e que atendem estudantes universitários.

Tucker \& Lauber (1995) ressaltam outra opção: a possibilidade de concessão de créditos tributários para Imposto de Renda ou para o Imposto sobre a Propriedade para cada unidade monetária gasta em educação pelas famílias. Em 2011, no Brasil, era possível deduzir no máximo R\$2.830,84 em despesas com qualquer forma de instrução, independente do número de dependentes. Considerando uma alíquota marginal em 2011 de 27,5\%, um chefe de família com rendimentos anuais iguais a $\mathrm{R} \$ 50.000,00$ e que gastasse mais do que $\mathrm{R} \$ 2.830,84$ com educação, teria um crédito tributário de $\mathrm{R} \$ 778.48$ por ano. Esse valor é bem inferior ao "piso nacional" por aluno da rede pública estipulado em R\$1.722,05 por ano. Além disso, esse incentivo fiscal é regressivo, isto é, famílias mais pobres, e que pagam menos impostos, têm créditos tributários menores. Portanto, da forma como tem sido praticada, essa política atinge principalmente as famílias de classe de média e alta, que já possuem maior liberdade de escolha acerca do setor educacional. Uma reformulação seria necessária para tornar progressivos os créditos tributários relacionados a deduções de gastos em educação.

Outra opção para ampliação das possibilidades de escolha das escolas pelas famílias de renda mais baixa consiste na concessão de incentivos fiscais para estabelecimentos particulares de Educação Básica que concedam bolsas de estudos para famílias com pouco poder aquisitivo. Nesse caso, o incentivo fiscal é similar ao concedido às Instituições de Ensino Superior (IES) que aderiram ao Prouni. ${ }^{17}$ Um mecanismo semelhante é mencionado por Tucker \& Lauber (1995), e consiste na constituição de fundos por agentes privados com recursos provenientes de doações para a provisão de vouchers para alunos de baixa renda.

Tais mecanismos permitem a escolha entre escolas das redes privada e pública, mas outros mecanismos de ampliação das escolhas entre escolas públicas também existem e, apesar da discussão sobre esses mecanismos fugir do escopo deste estudo, alguns dos exemplos mais importantes podem ser mencionados resumidamente. Por exemplo, para Urquiola (2005) e Hoxby (2000) o mecanismo de escolha de Tiebout ${ }^{18}$ é o mais poderoso mecanismo de promoção da eficiência alocativa e produtiva. Esse mecanismo pressupõe que as famílias se sorteiam entre os distritos que provêm os níveis (ou qualidade) de educação mais próximos de suas preferências. Esse mecanismo será mais efetivo quanto maior a descentralização na provisão da educação.

Outro exemplo de programa de ampliação da escolha entre escolas públicas encontrado principalmente nos Estados Unidos refere-se às Charter Schools, que consistem em escolas com autonomia administrativa (com liberdade para contratação, demissão, elaboração do currículo escolar, admissão

\footnotetext{
${ }^{17}$ Este incentivo fiscal para Instituições de Ensino Superior foi estabelecido pela Lei no 11.09605 e incide sobre imposto de renda da pessoa jurídica, contribuições social sobre o lucro líquido, Contribuição Social para Financiamento da Seguridade Social (COFINS) e Contribuição ao Programa de Integração Social (PIS).

${ }^{18}$ Referente a Tiebout (1956).
} 
e seleção de estudantes) que podem constituir alternativas às escolas públicas. Tucker \& Lauber (1995) destacam também as escolas denominadas "Magnet Schools", constituídas com o objetivo de promover programas específicos como aqueles em que se almeja maior integração e balanceamento étnico nos distritos. Outros programas consistem na permissão aos pais de escolherem qualquer escola dentro do distrito escolar em que residem. Há também programas que permitem a escolha de qualquer escola pública entre os vários distritos escolares. ${ }^{19}$ Contudo, como salientam Betts et al. (2006), as evidências empíricas sugerem que tais mecanismos resultam em pouca ou nenhuma melhoria no desempenho dos estudantes. Esses mecanismos de ampliação das escolhas entre escolas públicas são bastante interessantes, mas no caso brasileiro envolveriam a reestruturação dos sistemas de ensino, que deveriam proporcionar maior autonomia a grupos de escolas na formulação dos currículos, na arrecadação e administração dos recursos, que atualmente fica a cargo das secretarias de educação locais.

São muitas as alternativas de políticas disponíveis para ampliar as escolhas das famílias. A implantação dessas políticas têm dificuldades implícitas que deveriam ser exploradas mais profundamente. Contudo, constituem também oportunidades de aumentar a eficiência alocativa e produtiva do setor educacional.

\section{Conclusão}

O objetivo principal deste trabalho é verificar se há algum diferencial de produtividade entre os setores privado e público, e se esse diferencial de produtividade (ou de desempenho esperado) é levado em conta pelas famílias dos alunos para escolher a escola dos filhos. Esses dois fatores são cruciais para se considerar a introdução de políticas públicas educacionais que ampliem as possibilidades de escolha das famílias e reduzam as ineficiências associadas à provisão do bem in-kind. Sem esses diferenciais de produtividade, ou se as famílias não se importarem com isso devido a algum problema de informação, então, não faz sentido proceder com a discussão para o Brasil. Uma das hipóteses é a de que o setor privado é mais eficiente (mais produtivo). A outra é a de que as famílias têm expectativas racionais (conforme Goldhaber (1996)) e, portanto, são capazes de identificar os diferenciais de desempenho esperado para os seus filhos em cada setor, e incorporam essa informação em seus processos de escolha da escola. Tal diferencial de produtividade pode ser entendido como uma medida de qualidade relativa da educação oferecida por cada setor.

Para isso, este estudo estima as funções de produção para os dois setores pelo modelo de Heckman (1979) para amostras de matemática e leitura do SAEB 2003. Com esses resultados, são obtidos os desempenhos esperados para cada aluno em cada setor e obtém-se a diferença de produtividade entre setores. Os resultados mostram que o setor privado é significativamente mais produtivo, sustentando uma das hipóteses do trabalho.

Adicionalmente, no modelo de escolha do setor (Probit Estrutural), verifica-se que quanto maior o diferencial de produtividade intersetorial em favor do setor privado, maior é a probabilidade de as famílias escolherem uma

\footnotetext{
${ }^{19}$ Ver Tucker \& Lauber (1995) para uma lista com os tipos de programas de ampliação das escolhas e os estados americanos que implementaram cada tipo de programa.
} 
escola privada para seus filhos, o que sustenta a hipótese segundo a qual os pais são capazes de identificar tal diferencial e usarem essa informação para tomarem suas decisões.

Além disso, usando dados do Censo do Magistério de 2003, do Censo da Educação Básica 2003 e do SAEB 2003, foi possível construir uma variável referente ao diferencial de cor entre as escolas dos setores privado e público escolhidas ou factíveis de serem escolhidas pela família (ver Tabela A.1 para uma descrição da metodologia de construção das variáveis). O mesmo pode ser feito em relação à diferença de nível socioeconômico. Como esperado, os resultados mostram que quanto maiores os diferenciais de cor e de nível socioeconômico entre os setores privado e público factíveis de escolha, maior é a probabilidade de a família optar por uma escola privada.

Avaliando o indivíduo médio, verificou-se que a probabilidade de este frequentar a escola pública é muito grande, refletindo a vulnerabilidade socioeconômica do indivíduo médio brasileiro. Para que este fosse indiferente entre a rede pública e a privada, o diferencial de produtividade em matemática ou leitura deveria ser muito grande ( 1 desvio-padrão para matemática e pouco mais de meio desvio-padrão para leitura). Analisando as diferentes classes sociais (dividindo a amostra em quartos de renda), o resultado evidencia a desigualdade no Brasil. Somente os alunos do quarto mais rico apresentam uma probabilidade maior do que $50 \%$ de frequentar o setor privado. $\mathrm{O}$ aluno representativo do $3^{\circ}$ quarto (o $2^{\circ}$ mais rico) tem menos de $15 \%$ de probabilidade de frequentar escolas privadas (tanto na amostra de matemática quanto na de leitura). Em face da vulnerabilidade socioeconômica dos alunos mais pobres ( $1^{\circ}$ quarto), o diferencial de produtividade entre os setores deveria ser maior do que 1 desvio-padrão (Tabela 2) para que os alunos mais pobres ficassem indiferentes entre os dois setores.

Finalmente, diversas políticas podem ser consideradas para aumentar as opções de escolha entre os setores educacionais. Vouchers, créditos tributários, isenções fiscais às empresas, constituição de fundos formados com recursos públicos ou doações (via incentivos fiscais) e desenvolvimento do mercado de crédito, são alguns exemplos. Tais políticas têm o potencial de aumentar as eficiências alocativa e produtiva, levando a uma melhoria paretiana da economia. No entanto, é importante frisar as dificuldades inerentes à implementação de cada uma dessas propostas. Além disso, não há evidências empíricas conclusivas a respeito da capacidade destas em aumentarem a eficiência produtiva das escolas, i.e., as evidências do sucesso dessas políticas em aumentarem o desempenho dos alunos são pouco esclarecedoras, especialmente devido ao conhecimento ainda limitado sobre peer effects. A discussão sobre a efetividade dessas políticas em aumentar o desempenho dos alunos não são o foco desse estudo, mas constituem um tema desafiador para a agenda de pesquisas da área de economia da educação.

\section{Referências Bibliográficas}

Anand, P., Mizala, A. \& Repetto, A. (2009), 'Using school scholarships to estimate the effect of government subsidized private education on academic achievement in chile', Economics of Education Review 28, 370-381.

Betts, J. R., Rice, L. A., Zau, A. C. \& Tang, Y. E. (2006), 'Does school choice work? effects on student integration and achievement', Public Policy Insti- 
tute of California.

Curi, A. Z. \& Menezes Filho, N. A. (2009), 'Os determinantes dos gastos com educação no brasil', XXXVII Encontro Nacional de Economia.

Estevan, F. (2009), 'The quality of public education and private school enrollment: an assessment using brazilian data', Department of Economics - The Institute for Economic Development Working Papers Series.

França, M. T. A. \& Gonçalves, F. O. (2009), 'Provisão pública e privada de educação fundamental: diferenças de qualidade medidas através de propensity score matching', XXXI Encontro Nacional de Econometria.

Goldhaber, D. (1996), 'Public and private high schools: Is school choice an answer to the productivity problem', Economics of Education Review 15, 93109.

Goldhaber, D. (1999), 'An endogenous model of public school expenditures and private school enrollment', Journal of Urban Economics 46, 106-128.

Gruber, J. (2009), Public Finance and Public Policy, 2 edn, Worth Publishers, new York.

Heckman, J. (1979), 'Sample selection bias as a specification error', Econometrica $47,153-161$.

Hoxby, C. (2000), 'Does competition among public schools benefit students and taxpayers?', The American Economic Review 90(5), 1209-1238.

James, E. (1993), 'Why do different countries choose a different publicprivate mix of educational services?', JHR-The Journal of Human Resources 28(3), 571-592.

Jimenez, E. \& Sawada, Y. (2001), 'Public for private: The relationship between public and private school enrollment in the philippines', Economics of Education Review 20(4), 389-399.

Krueger, A. B. \& Zhu, P. (2004), 'Another look at the new york city voucher experiment', Behavioral Scientist 47(5), 658-698.

Levin, H. M. (1991), 'The economics of educational choice', Economics of Education Review 10(2), 137-158.

Long, J. E. \& Toma, E. F. (1988), 'The determinants of private school attendance, 1970-1980', The Review of Economics and Statistics 70(2), 351-357.

Mayer, D. P., Peterson, P., Myers, D. E., Tuttle, C. C. \& Howell, W. G. (2002), 'School choice in new york city after three years: An evaluation of the school choice scholarships program'.

McEwan, P. J. (2001), 'The effectiveness of public, catholic, and non-religious private schools in chile's voucher system', Education Economics 9(2), 103-128.

McEwan, P. J. \& Carnoy, M. (2000), 'The effectiveness and efficiency of private schools in chile's voucher system', Educational Evaluation and Policy Analysis 22, 213-239. 
Oliveira, P. R., Belluzzo, W. \& Pazello, E. T. A. (2009), 'Public-private sector diferentials in brazilian education: a counterfactual decomposition approach', XXXI Encontro Nacional de Econometria.

Rivkin, S. G., Hanushek, E. A. \& Kain, J. F. (2005), 'Teachers, schools, and academic achievement', Econometrica 73(2), 417-458.

Rouse, C. E. (1998), 'Private school vouchers and student achievement: An evaluation of the milwaukee parental choice program', Quarterly Journal of Economics 113, 553-602.

Tiebout, C. M. (1956), 'A pure theory of local expenditures', The Journal of Political Economy 64(5), 416-424.

Tucker, A. M. \& Lauber, W. F. (1995), 'A pure theory of local expenditures', The Heritage Foundation.

Urquiola, M. (2005), 'Does school choice lead to sorting? evidence from tiebout variation', The American Economic Review 95(4), 1310-1326. 


\section{Apêndice A}

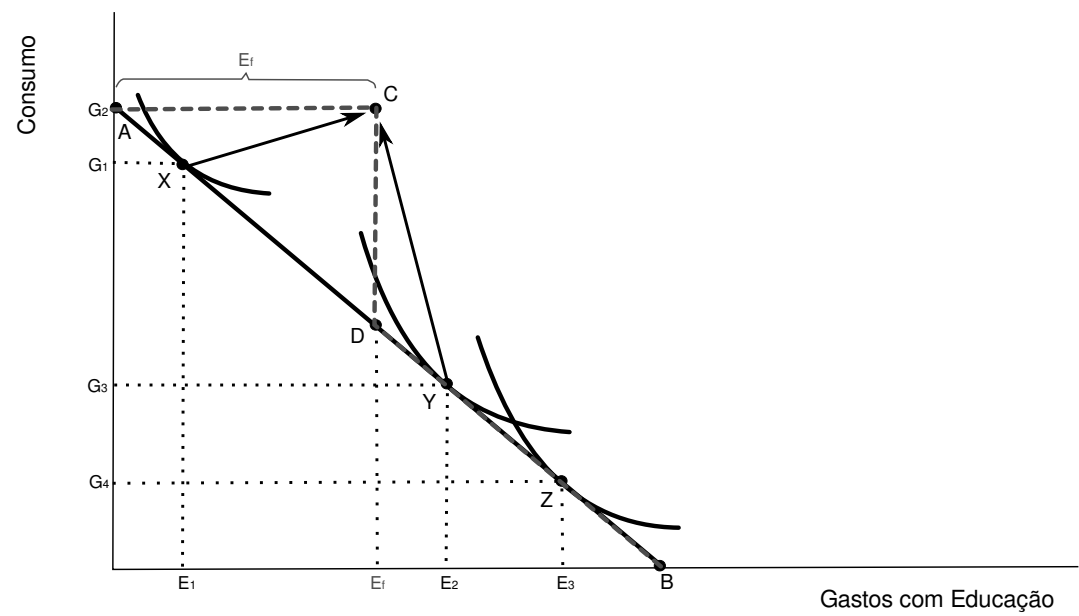

Fonte: Gruber (2009)

Figura A.1: Provisão pública de educação in-kind

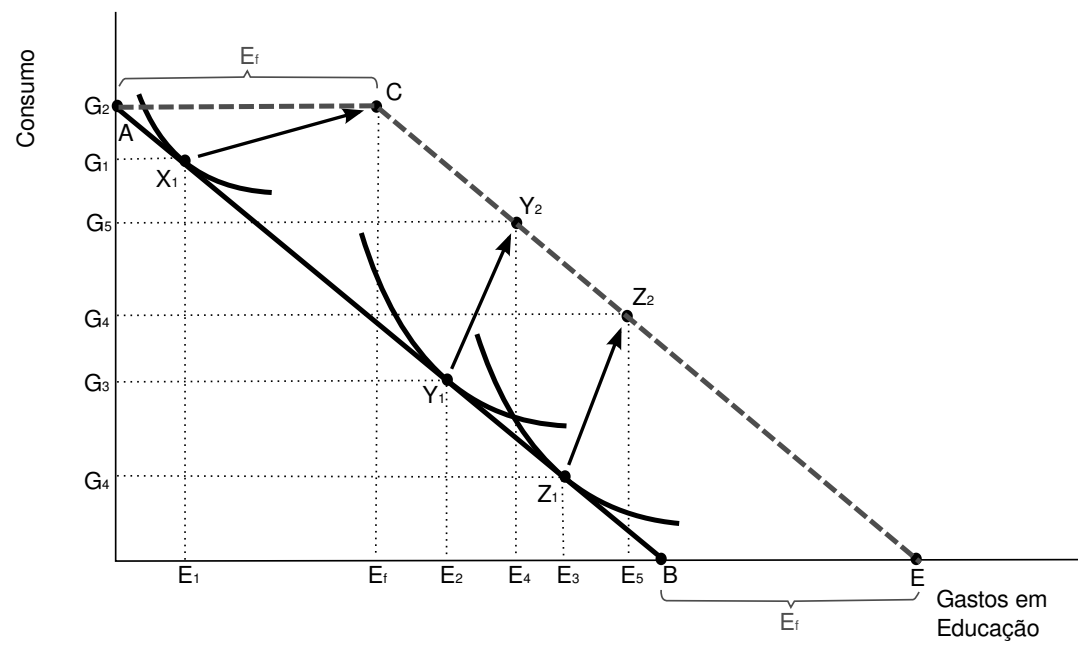

Fonte: Gruber (2009)

Figura A.2: Transferência monetária condicionada ao consumo de educação 
Tabela A.1: Definição das Variáveis

\begin{tabular}{|c|c|}
\hline Variáveis & $\begin{array}{l}\text { Descrição das variáveis - Descrição / (Fonte) / (Modelo em que foi } \\
\text { utilizada) }\end{array}$ \\
\hline $\begin{array}{l}\text { Proficiência } D \\
\text { sexo }\end{array}$ & $\begin{array}{l}\text { Proficiência em Matemática e Leitura / (SAEB) / (Heckman) } \\
\text { dummy que assume valor igual a } 1 \text { se o aluno é do sexo feminino / } \\
\text { (SAEB) / (Heckmane Probit Estrutural) }\end{array}$ \\
\hline branco & $\begin{array}{l}\text { dummy que assume valor igual a } 1 \text { se o aluno é da cor branca / (SAEB) } \\
\text { / (Heckman e Probit Estrutural) }\end{array}$ \\
\hline atrasado & $\begin{array}{l}\text { variável dummy que identifica se o aluno não tem a idade adequada e } \\
\text { nem é adiantado para a série que frequenta de acordo com o conceito } \\
\text { de idade escolar / (SAEB) / (Heckman) }\end{array}$ \\
\hline preescola & $\begin{array}{l}\text { dummy que identifica se o aluno freqüentou a creche ou a pré-escola / } \\
\text { (SAEB) / (Heckman) }\end{array}$ \\
\hline maeausente & $\begin{array}{l}\text { dummy que assume valor igual a } 1 \text { se o aluno não mora com a mãe / } \\
\text { (SAEB) / (Heckman e Probit Estrutural) }\end{array}$ \\
\hline paiausente & $\begin{array}{l}\text { dummy que assume valor igual a } 1 \text { se o aluno não mora com o pai / } \\
\text { (SAEB) / (Heckman e Probit Estrutural) }\end{array}$ \\
\hline escmae $8 \mathrm{a} 10$ & $\begin{array}{l}\text { dummy que assume valor igual a } 1 \text { caso a mãe do aluno tenha escolari- } \\
\text { dade entre } 8 \text { e } 10 \text { anos / (SAEB) / (Heckman e Probit Estrutural) }\end{array}$ \\
\hline escmae11a14 & $\begin{array}{l}\text { dummy que assume valor igual a } 1 \text { caso a mãe do aluno tenha escolari- } \\
\text { dade entre } 11 \text { e } 14 \text { anos / (SAEB) / (Heckman e Probit Estrutural) }\end{array}$ \\
\hline escmae15oumais & $\begin{array}{l}\text { dummy que assume valor igual a } 1 \text { caso a mãe do aluno tenha escolari- } \\
\text { dade igual a } 15 \text { anos ou mais / (SAEB) / (Heckman e Probit Estrutural) }\end{array}$ \\
\hline escpai8a10 & $\begin{array}{l}\text { dummy que assume valor igual a } 1 \text { caso o pai do aluno tenha escolari- } \\
\text { dade entre } 8 \text { e } 10 \text { anos / (SAEB) / (Heckman e Probit Estrutural) }\end{array}$ \\
\hline escpai11a14 & $\begin{array}{l}\text { dummy que assume valor igual a } 1 \text { caso o pai do aluno tenha escolari- } \\
\text { dade entre } 11 \text { e } 14 \text { anos / (SAEB) / (Heckman e Probit Estrutural) }\end{array}$ \\
\hline escpai15oumais & $\begin{array}{l}\text { dummy que assume valor igual a } 1 \text { caso o pai do aluno tenha escolari- } \\
\text { dade igual a } 15 \text { anos ou mais / (SAEB) / (Heckman e Probit Estrutural) }\end{array}$ \\
\hline rendapcpt & $\begin{array}{l}\text { renda familiar per capita estimada por Mínimos Quadrados Ordinários } \\
\text { com informações presentes nos bancos da PNAD e do SAEB das famí- } \\
\text { lias dos alunos que freqüentavam a 8a série do Ensino Fundamental / } \\
\text { (PNAD e SAEB) / (Heckman e Probit Estrutural) }\end{array}$ \\
\hline mensalidade & $\begin{array}{l}\text { mensalidade escolar estimada por Mínimos Quadrados Ordinários com } \\
\text { informações das famílias dos alunos que freqüentavam entre a } 5 \text { a e a } 8 \text { a } \\
\text { séries do Ensino Fundamental que estivessem presentes nos bancos da } \\
\text { POF e do SAEB / (POF e SAEB) / (Probit Estrutural) }\end{array}$ \\
\hline tamanhofamilia & $\begin{array}{l}\text { variável que indica o tamanho da família do aluno / (SAEB) / (Heckman } \\
\text { e Probit Estrutural) }\end{array}$ \\
\hline tamanhofamiliaqdrd & $\begin{array}{l}\text { variável que indica o tamanho da família do aluno ao quadrado / (SAEB) } \\
\text { / (Heckman) }\end{array}$ \\
\hline infradomestica & $\begin{array}{l}\text { Varia de } 0 \text { a } 4 \text { e representa a soma de itens presentes no domicílio que } \\
\text { refletem uma preocupação com a educação (computador, se tem mais } \\
\text { do que } 20 \text { livros, se tem assinatura de jornal e se tem assinatura de } \\
\text { revistas) / (SAEB) / (Heckman e Probit Estrutural) }\end{array}$ \\
\hline tamanhoturma & $\begin{array}{l}\text { variável que identifica o tamanho da turma do aluno / (SAEB) / (Heck- } \\
\text { man) }\end{array}$ \\
\hline tamanhoturmaqdrd & $\begin{array}{l}\text { variável que identifica o tamanho da turma do aluno ao quadrado / } \\
\text { (SAEB) / (Heckman) }\end{array}$ \\
\hline exuniv50 & $\begin{array}{l}\text { varável dummy que identifica se o professor do aluno espera que mais } \\
\text { da metade da turma vá para a universidade / (SAEB) / (Heckman) }\end{array}$ \\
\hline
\end{tabular}

Fonte: Elaboração Própria 
Tabela A.1: Definição das Variáveis (continuação)

\begin{tabular}{|c|c|}
\hline Variáveis & $\begin{array}{l}\text { Descrição das variáveis - Descrição / (Fonte) / (Modelo em que foi } \\
\text { utilizada) }\end{array}$ \\
\hline crithomorend & $\begin{array}{l}\text { variável dummy que identifica se a escola do aluno forma turmas se- } \\
\text { gundo à homogeneidade do rendimento escolar / (SAEB) / (Heckman) }\end{array}$ \\
\hline reforço & $\begin{array}{l}\text { variável dummy que identifica se a escola do aluno realiza reforço de } \\
\text { aprendizagem / (SAEB) / (Heckman) }\end{array}$ \\
\hline profbranco & $\begin{array}{l}\text { variável dummy que identifica se o professor do aluno é da cor branca } \\
\text { / (SAEB) / (Heckman) }\end{array}$ \\
\hline profposmais 360 & $\begin{array}{l}\text { variável dummy que identifica se o professor do aluno frequentou pós- } \\
\text { graduação com duração de no mínimo } 360 \text { horas / (SAEB) / (Heckman) }\end{array}$ \\
\hline $\exp 10+$ & $\begin{array}{l}\text { variável dummy que identifica se o professor do aluno leciona há } 10 \\
\text { anos ou mais / (SAEB) / (Heckman) }\end{array}$ \\
\hline trabmaisde $30 \mathrm{~h}$ & $\begin{array}{l}\text { variável dummy que identifica se o professor do aluno trabalha mais do } \\
\text { que } 30 \text { horas semanais / (SAEB) / (Heckman) }\end{array}$ \\
\hline contratoprecario & $\begin{array}{l}\text { variável dummy que identifica se o professor do aluno trabalha sob con- } \\
\text { trato temporário ou sem contrato / (SAEB) / (Heckman) }\end{array}$ \\
\hline salaarejada & $\begin{array}{l}\text { variável dummy que identifica se as salas de aula da escola do aluno são } \\
\text { arejadas / (SAEB) / (Heckman) }\end{array}$ \\
\hline segurança & $\begin{array}{l}\text { variável dummy que identifica se a escola do aluno adota medidas de } \\
\text { segurança (muros, grades, controle de entrada e de saída, e vigilância } \\
\text { no turno de aula) / (SAEB) / (Heckman) }\end{array}$ \\
\hline razaoescolaspop & $\begin{array}{l}\text { Razão entre o total de escolas privadas e a população na faixa etária de } \\
11 \text { a } 15 \text { anos do município. Consiste na variável excluída da equação } \\
\text { principal do modelo de Heckman, e incluída na equação de seleção ( } 1^{\circ} \\
\text { estágio) / (Censo Escolar e Projeção Populacional) / (Heckman e Probit } \\
\text { Estrutural) }\end{array}$ \\
\hline difprofic & $\begin{array}{l}\text { Diferença entre a proficiência estimada na rede privada e a proficiên- } \\
\text { cia estimada na rede pública para um aluno i. É obtida pela diferença } \\
\text { entre o valor predito com base na equação referente ao setor privado } \\
\text { dadas suas características e a nota esperada desse aluno de acordo com } \\
\text { os retornos obtidos pela estimação dos paramentos do setor público / } \\
\text { (estimada) / (Probit Estrutural) }\end{array}$ \\
\hline DNSE & $\begin{array}{l}\text { Diferença entre o nível sócio-econômico das redes privada e pública. O } \\
\text { indicador do setor escolhido é igual ao da escola escolhida, e o indicador } \\
\text { do setor alternativo (não escolhido) é a média do indicador da rede não } \\
\text { escolhida no município ou na micro-região (quando a rede não estiver } \\
\text { presente no município). Este indicador assume valor de } 1 \text { a } 7 \text {. Cada } \\
\text { valor denota a classe sócio-econômica predominante na escola. O valor } \\
1 \text { denota "Muito Pobres", } 2 \text { denota "Pobres", } 3 \text { se refere a "Classe Média } \\
\text { Baixa", } 4 \text { denota "Todas as classes", } 5 \text { se refere a "Classe Média", } 6 \text { se } \\
\text { refere a "Classe Média Alta", e } 7 \text { denota "Ricos" / (Censo do Magistério) } \\
\text { / (Probit Estrutural) }\end{array}$ \\
\hline Dbranco & $\begin{array}{l}\text { Diferença entre o percentual de brancos da rede privada e da rede pú- } \\
\text { blica. Da mesma forma que na variável DNSE, o percentual de brancos } \\
\text { do setor alternativo, ou seja, aquele não escolhido, é obtida pela média } \\
\text { do setor no município (ou na micro-região quando não houvesse escola } \\
\text { do setor alternativo no município) / (Censo Escolar) / (Probit Estrutu- } \\
\text { ral) }\end{array}$ \\
\hline
\end{tabular}




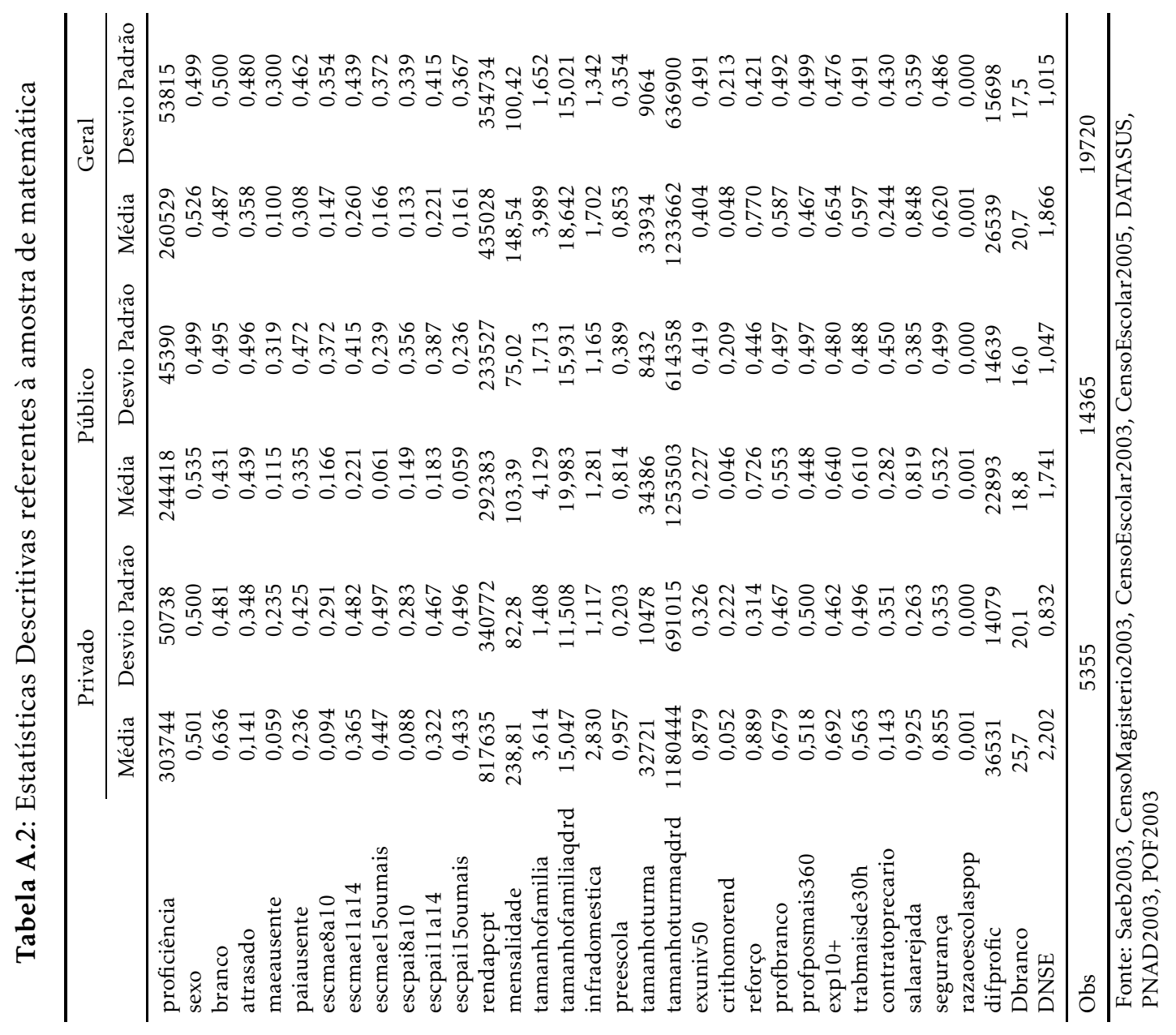




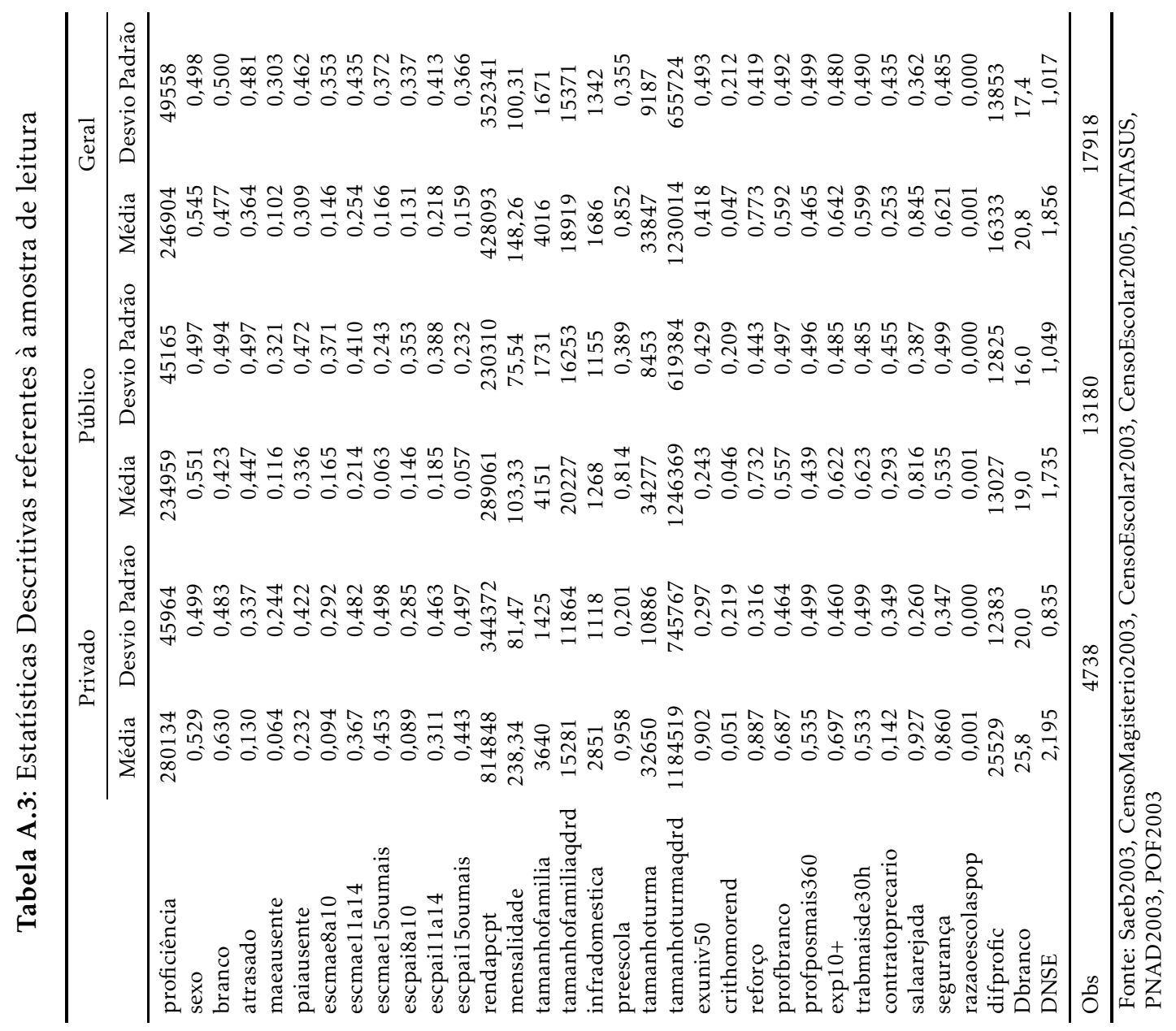


Tabela A.4: Estimativas do $1^{\circ}$ estágio do modelo de seleção de Heckman

\begin{tabular}{|c|c|c|}
\hline & $\begin{array}{l}\text { Matemática (Privada } \\
=1 ; \text { Pública }=0)\end{array}$ & $\begin{array}{l}\text { Leitura (Privada }=1 ; \\
\text { Pública }=0)\end{array}$ \\
\hline sexo & $\begin{array}{l}0,039 \\
(0,026)\end{array}$ & $\begin{array}{l}0,016 \\
(0,026)\end{array}$ \\
\hline branco & $\begin{array}{l}0,099^{* * *} \\
(0,027)\end{array}$ & $\begin{array}{l}0,116^{* * *} \\
(0,028)\end{array}$ \\
\hline atrasado & $\begin{array}{l}-0,392^{* * *} \\
(0,031)\end{array}$ & $\begin{array}{c}-0,463^{* * *} \\
(0,032)\end{array}$ \\
\hline maeausente & $\begin{array}{l}-0,167^{* * *} \\
(0,048)\end{array}$ & $\begin{array}{r}-0,060 \\
(0,049)\end{array}$ \\
\hline paiausente & $\begin{array}{c}-0,112^{* * *} \\
(0,031)\end{array}$ & $\begin{array}{c}-0,068^{* *} \\
(0,031)\end{array}$ \\
\hline escmae $8 \mathrm{a} 10$ & $\begin{array}{l}0,378^{* * *} \\
(0,043)\end{array}$ & $\begin{array}{l}0,354^{* * *} \\
(0,044)\end{array}$ \\
\hline escmae11a14 & $\begin{array}{l}0,500^{* * *} \\
(0,038)\end{array}$ & $\begin{array}{l}0,552^{* * *} \\
(0,039)\end{array}$ \\
\hline escmae15oumais & $\begin{array}{l}0,409^{* * *} \\
(0,049)\end{array}$ & $\begin{array}{l}0,454^{* * *} \\
(0,050)\end{array}$ \\
\hline escpai8a10 & $\begin{array}{l}0,209^{* * *} \\
(0,045)\end{array}$ & $\begin{array}{l}0,230^{* * *} \\
(0,046)\end{array}$ \\
\hline escpai11a14 & $\begin{array}{l}0,422^{* * *} \\
(0,040)\end{array}$ & $\begin{array}{l}0,343^{* * *} \\
(0,040)\end{array}$ \\
\hline escpai15oumais & $\begin{array}{l}0,295^{* * *} \\
(0,050)\end{array}$ & $\begin{array}{l}0,177^{* * *} \\
(0,050)\end{array}$ \\
\hline rendapcpt & $\begin{array}{l}0,002^{* * *} \\
(0,000)\end{array}$ & $\begin{array}{l}0,002^{* * *} \\
(0,000)\end{array}$ \\
\hline tamanhofamilia & $\begin{array}{l}-0,087^{* * *} \\
(0,029)\end{array}$ & $\begin{array}{r}-0,062^{* *} \\
(0,029)\end{array}$ \\
\hline tamanhofamiliaqdrd & $\begin{array}{l}0,005 \\
(0,003)\end{array}$ & $\begin{array}{l}0,005 \\
(0,003)\end{array}$ \\
\hline infradomestica & $\begin{array}{l}0,117^{* * *} \\
(0,013)\end{array}$ & $\begin{array}{l}0,121^{* * *} \\
(0,013)\end{array}$ \\
\hline preescola & $\begin{array}{l}0,246^{* * *} \\
(0,045)\end{array}$ & $\begin{array}{l}0,300^{* * *} \\
(0,050)\end{array}$ \\
\hline tamanhoturma & $\begin{array}{l}-0,150^{* * *} \\
(0,006)\end{array}$ & $\begin{array}{l}-0,156^{* * *} \\
(0,007)\end{array}$ \\
\hline tamanhoturmaqdrd & $\begin{array}{l}0,002^{* * *} \\
(0,000)\end{array}$ & $\begin{array}{l}0,002^{* * *} \\
(0,000)\end{array}$ \\
\hline exuniv 50 & $\begin{array}{l}1,395^{* * *} \\
(0,027)\end{array}$ & $\begin{array}{l}1,445^{* * *} \\
(0,028)\end{array}$ \\
\hline crithomorend & $\begin{array}{l}0,227^{* * *} \\
(0,061)\end{array}$ & $\begin{array}{l}0,319^{* * *} \\
(0,061)\end{array}$ \\
\hline reforço & $\begin{array}{l}0,134^{* * *} \\
(0,036)\end{array}$ & $\begin{array}{l}0,077^{* *} \\
(0,038)\end{array}$ \\
\hline profbranco & $\begin{array}{l}0,153^{* * *} \\
(0,028)\end{array}$ & $\begin{array}{l}0,052^{*} \\
(0,029)\end{array}$ \\
\hline profposmais 360 & $\begin{array}{c}-0,079^{* * *} \\
(0,027)\end{array}$ & $\begin{array}{l}0,093^{* * *} \\
(0,028)\end{array}$ \\
\hline $\exp 10+$ & $\begin{array}{c}-0,141^{\star * *} \\
(0,029)\end{array}$ & $\begin{array}{c}-0,232^{* * *} \\
(0,028)\end{array}$ \\
\hline trabmaisde $30 \mathrm{~h}$ & $\begin{array}{l}0,030 \\
(0,026)\end{array}$ & $\begin{array}{r}-0,037 \\
(0,026)\end{array}$ \\
\hline
\end{tabular}

Obs: ${ }^{*} p<0,10,{ }^{* *} p<0,05,{ }^{* * *} p<0,01$ 


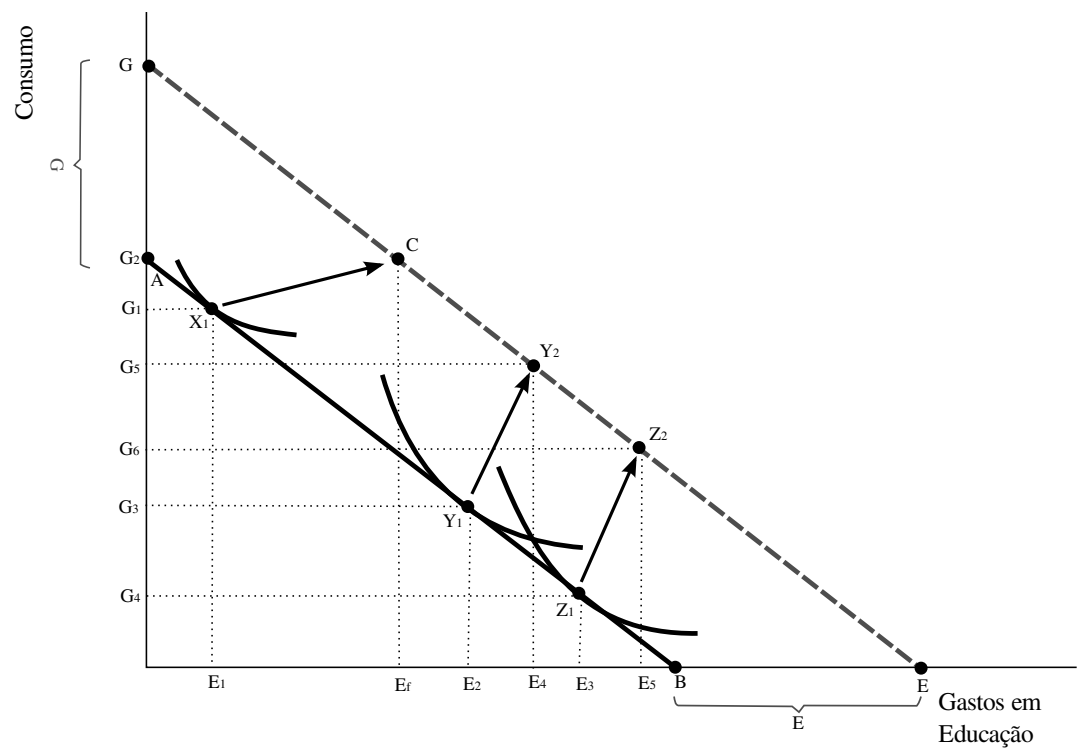

Fonte: Gruber (2009)

Figura A.3: Transferência monetária de propósito geral

Tabela A.4: Estimativas do $1^{\circ}$ estágio do modelo de seleção de Heckman (continuação)

\begin{tabular}{|c|c|c|}
\hline & $\begin{array}{l}\text { Matemática } \quad \text { (Privada } \\
=1 ; \text { Pública }=0)\end{array}$ & $\begin{array}{l}\text { Leitura (Privada }=1 ; \\
\text { Pública }=0 \text { ) }\end{array}$ \\
\hline contratoprecario & $\begin{array}{l}-0,215^{* * *} \\
(0,034)\end{array}$ & $\begin{array}{l}-0,409^{* * *} \\
(0,036)\end{array}$ \\
\hline salaarejada & $\begin{array}{l}0,455^{* * *} \\
(0,041)\end{array}$ & $\begin{array}{l}0,408^{* * *} \\
(0,042)\end{array}$ \\
\hline segurança & $\begin{array}{l}0,624^{* * *} \\
(0,031)\end{array}$ & $\begin{array}{l}0,643^{* * *} \\
(0,032)\end{array}$ \\
\hline razaoescolaspop & $\begin{array}{l}734698^{* * *} \\
-52832\end{array}$ & $\begin{array}{l}690946^{* * *} \\
-53206\end{array}$ \\
\hline Constante & $\begin{array}{l}-1,792^{* * *} \\
(0,156)\end{array}$ & $\begin{array}{l}-1,508^{* * *} \\
(0,160)\end{array}$ \\
\hline Dummies de UF & Sim & Sim \\
\hline$(-2) \times \log$ likelihood & 26028,41 & 25680715 \\
\hline LR chi quadrado & 1613,77 & 1439,84 \\
\hline
\end{tabular}

Obs: ${ }^{*} p<0,10,{ }^{* *} p<0,05,{ }^{* * *} p<0,01$ 
Tabela A.5: Estimativas das equações de desempenho usando o modelo de seleção de Heckman — $2^{\circ}$ estágio

\begin{tabular}{|c|c|c|c|c|}
\hline & \multicolumn{2}{|c|}{ Matemática } & \multicolumn{2}{|c|}{ Leitura } \\
\hline & Profic. Privada & Profic. Pública & Profic. Privada & Profic. Pública \\
\hline sexo & $\begin{array}{c}-10,189^{* * *} \\
(0,972)\end{array}$ & $\begin{array}{c}-12,303^{* * *} \\
(0,641)\end{array}$ & $\begin{array}{c}14,812^{* * *} \\
(0,933)\end{array}$ & $\begin{array}{c}11,914^{* * *} \\
(0,664)\end{array}$ \\
\hline branco & $\begin{array}{c}2,402^{* *} \\
-1,081\end{array}$ & $\begin{array}{l}2,003^{* * *} \\
(0,689)\end{array}$ & $\begin{array}{l}1,661 \\
-1,016\end{array}$ & $\begin{array}{c}1,568^{* *} \\
(0,714)\end{array}$ \\
\hline atrasado & $\begin{array}{c}-28,150^{* * *} \\
-1,603\end{array}$ & $\begin{array}{c}-15,594^{* * *} \\
(0,669)\end{array}$ & $\begin{array}{c}-24,222^{* * *} \\
-1,498\end{array}$ & $\begin{array}{c}-15,956^{* * *} \\
(0,705)\end{array}$ \\
\hline maeausente & $\begin{array}{l}-6,437^{* * *} \\
-2,096\end{array}$ & $\begin{array}{l}-2,895^{* * *} \\
-1,023\end{array}$ & $\begin{array}{r}-1,837 \\
-1,905\end{array}$ & $\begin{array}{c}-3,778^{* * *} \\
-1,076\end{array}$ \\
\hline paiausente & $\begin{array}{r}-1,969 \\
-1,240\end{array}$ & $\begin{array}{r}-0,428 \\
(0,758)\end{array}$ & $\begin{array}{l}1,212 \\
-1,162\end{array}$ & $\begin{array}{l}1,850^{* *} \\
(0,795)\end{array}$ \\
\hline escmae8a10 & $\begin{array}{l}2,596 \\
-2,537\end{array}$ & $\begin{array}{l}3,450^{* * *} \\
(0,907)\end{array}$ & $\begin{array}{c}-5,054^{* *} \\
-2,441\end{array}$ & $\begin{array}{l}2,737^{* * *} \\
(0,965)\end{array}$ \\
\hline escmae11a14 & $\begin{array}{l}3,841 \\
-2,366\end{array}$ & $\begin{array}{l}5,162^{* * *} \\
(0,922)\end{array}$ & $\begin{array}{r}-0,405 \\
-2,204\end{array}$ & $\begin{array}{l}5,044^{* * *} \\
(0,959)\end{array}$ \\
\hline escmae15oumais & $\begin{array}{l}7,935^{* * *} \\
-2,454\end{array}$ & $\begin{array}{l}6,691^{* * *} \\
-1,915\end{array}$ & $\begin{array}{l}3,332 \\
-2,333\end{array}$ & $\begin{array}{l}5,103^{* * *} \\
-1,833\end{array}$ \\
\hline escpai8a10 & $\begin{array}{l}4,581^{*} \\
-2,361\end{array}$ & $\begin{array}{l}2,348^{* *} \\
(0,966)\end{array}$ & $\begin{array}{l}2,685 \\
-2,252\end{array}$ & $\begin{array}{l}2,707^{* * *} \\
-1,003\end{array}$ \\
\hline escpai11a14 & $\begin{array}{l}8,457^{* * *} \\
-2,152\end{array}$ & $\begin{array}{l}5,874^{* * *} \\
-1,018\end{array}$ & $\begin{array}{l}6,899^{* * *} \\
-1,936\end{array}$ & $\begin{array}{l}5,593^{* * *} \\
-1,033\end{array}$ \\
\hline escpai15oumais & $\begin{array}{l}9,289^{* * *} \\
-2,212\end{array}$ & $\begin{array}{l}8,199^{* * *} \\
-1,957\end{array}$ & $\begin{array}{l}10,127^{* * *} \\
-2,071\end{array}$ & $\begin{array}{l}7,211^{* * *} \\
-1,958\end{array}$ \\
\hline rendapcpt & $\begin{array}{l}0,017^{* * *} \\
(0,003)\end{array}$ & $\begin{array}{l}0,015^{* * *} \\
(0,003)\end{array}$ & $\begin{array}{l}0,007^{* * *} \\
(0,003)\end{array}$ & $\begin{array}{l}0,007^{* *} \\
(0,003)\end{array}$ \\
\hline tamanhofamilia & $\begin{array}{l}5,122^{* * *} \\
-1,270\end{array}$ & $\begin{array}{c}0,665 \\
(0,658)\end{array}$ & $\begin{array}{l}2,203^{*} \\
-1,212\end{array}$ & $\begin{array}{l}2,941^{* * *} \\
(0,727)\end{array}$ \\
\hline tamanhofamiliaqdrd & $\begin{array}{c}-0,794^{* * *} \\
(0,157)\end{array}$ & $\begin{array}{c}-0,175^{* *} \\
(0,069)\end{array}$ & $\begin{array}{c}-0,572^{* * *} \\
(0,142)\end{array}$ & $\begin{array}{c}-0,463^{* * *} \\
(0,076)\end{array}$ \\
\hline infradomestica & $\begin{array}{l}0,919 \\
(0,582)\end{array}$ & $\begin{array}{l}0,196 \\
(0,344)\end{array}$ & $\begin{array}{l}2,438^{* * *} \\
(0,543)\end{array}$ & $\begin{array}{l}1,065^{* * *} \\
(0,352)\end{array}$ \\
\hline preescola & $\begin{array}{l}11,477^{* * *} \\
-2,506\end{array}$ & $\begin{array}{l}6,040^{* * *} \\
(0,813)^{* * *}\end{array}$ & $\begin{array}{l}12,336^{* * *} \\
-2,555\end{array}$ & $\begin{array}{l}7,004^{* * *} \\
(0,876)\end{array}$ \\
\hline tamanhoturma & $\begin{array}{l}0,874^{* * *} \\
(0,273)\end{array}$ & $\begin{array}{l}0,834^{* * *} \\
(0,187)\end{array}$ & $\begin{array}{c}0,243 \\
(0,231)\end{array}$ & $\begin{array}{l}0,668^{* * *} \\
(0,188)\end{array}$ \\
\hline tamanhoturmaqdrd & $\begin{array}{c}-0,009^{* *} \\
(0,004)\end{array}$ & $\begin{array}{l}-0,012^{* * *} \\
(0,003)\end{array}$ & $\begin{array}{r}-0,002 \\
(0,003)\end{array}$ & $\begin{array}{l}-0,011^{* * *} \\
(0,003)\end{array}$ \\
\hline exuniv50 & $\begin{array}{c}6,634^{* *} \\
-2,945\end{array}$ & $\begin{array}{l}4,096^{* * *} \\
(0,836)\end{array}$ & $\begin{array}{l}7,365^{* * *} \\
-2,420\end{array}$ & $\begin{array}{l}3,315^{* * *} \\
(0,889)\end{array}$ \\
\hline crithomorend & $\begin{array}{r}-2,932 \\
-2,117\end{array}$ & $\begin{array}{l}4,200^{* * *} \\
-1,535\end{array}$ & $\begin{array}{l}2,583 \\
-1,965\end{array}$ & $\begin{array}{l}0,599 \\
-1,563\end{array}$ \\
\hline reforço & $\begin{array}{c}5,398^{* * *} \\
-1,815\end{array}$ & $\begin{array}{l}2,355^{* * *} \\
(0,761)\end{array}$ & $\begin{array}{l}2,504 \\
-1,780\end{array}$ & $\begin{array}{l}3,426^{* * *} \\
(0,804)\end{array}$ \\
\hline profbranco & $\begin{array}{l}2,624^{* *} \\
-1,173\end{array}$ & $\begin{array}{l}1,338^{*} \\
(0,718)\end{array}$ & $\begin{array}{l}3,262^{* * *} \\
-1,079\end{array}$ & $\begin{array}{l}0,239 \\
(0,734)\end{array}$ \\
\hline profposmais 360 & $\begin{array}{l}1,060 \\
-1,042\end{array}$ & $\begin{array}{l}3,769^{* * *} \\
(0,699)\end{array}$ & $\begin{array}{l}0,610 \\
(0,981)\end{array}$ & $\begin{array}{l}1,293^{*} \\
(0,717)\end{array}$ \\
\hline $\exp 10+$ & $\begin{array}{r}-0,223 \\
-1,104\end{array}$ & $\begin{array}{l}2,943^{* * *} \\
(0,723)\end{array}$ & $\begin{array}{l}2,716^{* * *} \\
-1,040\end{array}$ & $\begin{array}{c}1,124 \\
(0,742)\end{array}$ \\
\hline
\end{tabular}

Obs: ${ }^{*} p<0,10,^{* *} p<0,05,{ }^{* * *} p<0,01$

Essas estimativas também foram realizadas pelo Método dos Mínimos Quadrados Ordinários (MQO), e podem ser sob requisição aos autores. 
Tabela A.5: Estimativas das equações de desempenho usando o modelo de seleção de Heckman - $2^{\circ}$ estágio (continuação)

\begin{tabular}{lcccc}
\hline & \multicolumn{2}{c}{ Matemática } & \multicolumn{2}{c}{ Leitura } \\
\cline { 2 - 5 } & Profic. Privada & Profic. Pública & Profic. Privada & Profic. Pública \\
\hline trabmaisde30h & 0,998 & $-2,810^{* * *}$ & $-0,978$ & $-1,619^{* *}$ \\
contratoprecario & $-1,018$ & $(0,679)$ & $(0,962)$ & $(0,704)$ \\
& $-3,114^{* *}$ & 0,828 & $-3,475^{* *}$ & $2,418^{* * *}$ \\
salaarejada & $-1,419$ & $(0,795)$ & $-1,386$ & $(0,818)$ \\
& $8,072^{* * *}$ & $3,345^{* * *}$ & $9,184^{* * *}$ & 1,044 \\
segurança & $-2,140$ & $(0,826)$ & $-1,994$ & $(0,856)$ \\
& $4,832^{* * *}$ & 0,200 & $4,168^{* * *}$ & 0,666 \\
Constante & $-1,766$ & $(0,675)$ & $-1,617$ & $(0,702)$ \\
Dummies de UF & $232436^{* * *}$ & $221617^{* * *}$ & $212450^{* * *}$ & $199479^{* * *}$ \\
\hline R.de Mills Invertida & $-8,810$ & $-4,463$ & $-7,207$ & $-4,451$ \\
Sim de Obs. & $-2,928$ & Sim & Sim & Sim \\
Obs. Censuradas & $-3,547$ & $8,838^{* * *}$ & 2,190 & $8,239^{* * *}$ \\
\hline
\end{tabular}

Obs: ${ }^{*} p<0,10,{ }^{* *} p<0,05,{ }^{* * *} p<0,01$

Essas estimativas também foram realizadas pelo Método dos Mínimos Quadrados Ordinários (MQO), e podem ser sob requisição aos autores.

Tabela A.6: Diferença entre as proficiências esperadas e seus contrafactuais por percentil da distribuição e na média - Amostra de Matemática

\begin{tabular}{llll}
\hline & Privado & Público & \multicolumn{1}{c}{ Geral } \\
\hline difprofic (média) & $36,531^{* * *}$ & $22,893^{* * *}$ & $26,539^{* * *}$ \\
& $(0,199)$ & $(0,138)$ & -0.108 \\
difprofic(p10) & $29,873^{* * *}$ & $12,554^{* * *}$ & $14,235^{* * *}$ \\
& $(0,574)$ & $(0,340)$ & $(0,274)$ \\
difprofic(p25) & $35,712^{* * *}$ & $18,009^{* * *}$ & $20,300^{* * *}$ \\
& $(0,440)$ & $(0,218)$ & $(0,240)$ \\
difprofic(p50) & $38,072^{* * *}$ & $24,213^{* * *}$ & $27,779^{* * *}$ \\
& $(0,340)$ & -0.236 & $(0,220)$ \\
difprofic(p75) & $40,192^{* * *}$ & $29,309^{* * *}$ & $33,453^{* * *}$ \\
& $(0,453)$ & $(0,274)$ & $(0,248)$ \\
difprofic(p90) & $39,755^{* * *}$ & $31,130^{* * *}$ & $38,068^{* * *}$ \\
& $(0,522)$ & $(0,298)$ & $(0,379)$ \\
\hline
\end{tabular}

Obs: ${ }^{*} p<0,10,{ }^{* *} p<0,05,{ }^{* * *} p<0,01$ 
Tabela A.7: Diferença entre as proficiências esperadas e seus contrafactuais por percentil da distribuição e na média - Amostra de Leitura

\begin{tabular}{llll}
\hline & Privado & Público & \multicolumn{1}{c}{ Geral } \\
\hline difprofic (média) & $25,529^{* * *}$ & $13,027^{* * *}$ & $16,333^{* * *}$ \\
& $(0,168)$ & $(0,113)$ & $(0,116)$ \\
difprofic(p10) & $17,542^{* * *}$ & $5,111^{* * *}$ & $6,480^{* * *}$ \\
& $(0,431)$ & $(0,254)$ & $(0,280)$ \\
difprofic(p25) & $23,474^{* * *}$ & $9,131^{* * *}$ & $10,618^{* * *}$ \\
& $(0,273)$ & $(0,247)$ & $(0,237)$ \\
difprofic(p50) & $26,647^{* * *}$ & $13,507^{* * *}$ & $16,400^{* * *}$ \\
& $(0,325)$ & $(0,206)$ & $(0,186)$ \\
difprofic(p75) & $29,235^{* * *}$ & $17,565^{* * *}$ & $21,910^{* * *}$ \\
& $(0,320)$ & $(0,218)$ & $(0,212)$ \\
difprofic(p90) & $31,420^{* * *}$ & $19,979^{* * *}$ & $26,680^{* * *}$ \\
& $(0,366)$ & $(0,287)$ & $(0,305)$ \\
\hline
\end{tabular}

Obs: ${ }^{*} p<0,10,{ }^{* *} p<0,05,{ }^{* * *} p<0,01$ 